[Preprint; final version published as: Matisoff, D. C., Noonan, D. S., \& O’Brien, J. J. (2013). Convergence in Environmental Reporting: Assessing the Carbon Disclosure Project. Business Strategy and the Environment, 22(5), 285-305. doi:10.1002/bse.1741]

\title{
Convergence in Environmental Reporting: Assessing the Carbon Disclosure Project
}

\section{Daniel C. Matisoff, Douglas S. Noonan, John J. O'Brien}

Keywords:

Information Disclosure, Voluntary Environmental Programs, Environmental Reporting, Transparency, Corporate Sustainability, Convergence 


\section{Abstract}

We perform content analysis on Carbon Disclosure Project (CDP) responses from 2003 to 2010, focusing on the extent to which firms account for indirect emissions and have exhibited convergence in carbon reporting. We also examine standardization in reporting and the variation of reporting behavior across industry and country. We find that the CDP has produced a mixed record of improved transparency. In some areas, such as scope 2 emissions, the CDP has demonstrated an increase in transparency in later years. However, the transparency and quality of direct emissions and scope 3 emissions have not improved over time. Japanese and EU firms have increased transparency, while U.S. firms have decreased transparency. Energy-intensive industries have either increased transparency or remained the same, while less energy-intensive industries have become less transparent. We demonstrate some evidence of a learning effect among firms after participating in the CDP survey.

\section{Introduction}

Strategic responses to climate change have varied immensely across firms. Some firms have been transparent and release detailed emissions data to the public. Other firms remain opaque, keeping carbon emissions, electricity use, and other climate-related business activities removed from public scrutiny. A wide array of research has addressed the determinants of corporate disclosure of environmental performance, sustainability, and carbon emissions (Peters and Romi, 2010; Cormier et al., 2005; Brammer and Pavelin, 2006; Kolk and Perego, 2010; Kolk, 2005; Haddock-Fraser and Fraser, 2008; Chen and Bouvain, 2009; Berthelot et al., 2003). In this paper, we examine trends relating to carbon disclosure and report on the extent to which firms have increased transparency over time across a wide range of emissions-related activities. In particular, we focus on Scope 2 and Scope 3 emissions, which include a broad array of indirect business activity and product lifecycle impacts, which have received much less attention from formal institutions than have Scope 1 (direct carbon emissions). Further, we examine the convergence and standardization of carbon reporting. We examine whether information reported by firms has become more standardized, as well as how transparency varies across industries. Additionally, we examine the extent to which firms have begun to use similar language regarding climate change. We demonstrate that the CDP has produced a mixed record of improved transparency. On one hand, public disclosures have improved in quality, particularly for Scope 2 emissions. On the other hand, an increasing percentage of disclosures remain available only to institutional investors, and while an increasing number of firms have disclosed Scope 1 and Scope 3 emissions, the percentage of firms disclosing quality information has not substantially increased over time. 


\section{Theory and Literature Review}

\subsection{Motivations for transparency and disclosure}

Significant attention has been paid to the relationship between information disclosure and transparency and improved management. For firm managers, improved information may lead to improved efficiency, reduction in waste, lower costs of capital, and improved shareholder value. For policymakers and government officials, improved transparency offers the opportunity to achieve low-cost environmental improvements without heavy-handed government intervention.

Empirical findings suggest that firms pursue an open disclosure policy due to investor (Reid and Toffel, 2009) or employee (Spence, 2009) pressure, legal liabilities and securities laws (Skinner, 1994),,increased growth rates and shareholder value (Lev, 1992; Blacconiere and Patten, 1994), improved terms of trade with suppliers and customers (Lev, 1992), reduced regulatory intervention (Lev, 1992; Walker and Salt, 2006), and reduced cost and increased access to capital (Blacconiere and Patten, 1994; Botosan, 1997). For example, in Botosan and Plumlee (2002), the authors find that reduced capital costs are limited to disclosures in annual reports, and that timely disclosures lead to increased stock price volatility and an increase of capital costs.

One perspective suggests that an array of managerial and economic incentives drive firm transparency. Firms voluntarily disclose in order to improve shareholder value (Lyon and Kim, 2011; Barber, 2007). If firm managers do not provide credible information, investors will either assume the worst or will have to spend more time collecting information from other information sources and stock prices will decrease (Cormier and Magnan, 2003). On the other hand, releasing environmental information involves releasing proprietary information such as environmentally related capital expenditures, fuel use, environmental investments, and other environmental liabilities or commitments (Cormier et al., 2005; Li et al., 1997; Berry, 1984; Peters and Romi, 2010).

A second perspective relates firm transparency to external institutional pressures (Knox-Hayes and Levy, 2011). While international governance efforts and the increasing globalization of commerce has led multinational business to be thought of as 'global' and 'stateless', empirical evidence demonstrates that much of the variation in firm reporting behavior can be attributed to national institutional characteristics, such as the stringency of the regulatory environment and the environmentalist culture of a country (Kolk, 2005; Walker and Salt, 2006; Peters and Romi, 2010). Industry factors are important, as well. Industries that engage in more polluting activity tend to be more likely to voluntarily disclose environmental information (Brammer and Pavelin, 2006). Firm-specific factors (e.g., size, profitability, degree leveraged, media exposure, ownership dispersion, participation on the board of directors by external stakeholders) increase firms' likelihood of voluntarily disclosing environmental information (Cormier and Magnan, 2003; Brammer and Pavelin, 2006; Prado-Lorenzo et al., 2009; Brammer and Pavelin, 2008; Stanny and Ely, 2008).

Previous research has demonstrated wide variations in strategic decision-making of firms related to carbon disclosure (Kolk and Pinske, 2004; Kolk and Pinske, 2005), carbon management (Kolk and Pinske, 2004; Kolk and Pinske, 2005; Sullivan, 2009), and investment in energy-efficient technologies (Hoffman, 2007). This variation can be explained by institutional, economic, and managerial determinants of information disclosure. While there is an emerging understanding of these pressures that lead to increased reporting, much less is known about the quality of firm 
reporting and the extent to which the disclosure of environmental performance leads to or reflects changes in behavior (Cormier et al., 2005; Chen and Bouvain, 2009). Indeed, several authors have called for increased investigation into the content of environmental disclosure, as well as extensions beyond a simple dichotomous measurement of reporting behavior (Kolk and Perego, 2010; Chen and Bouvain, 2009; Stiller and Daub, 2007).

\subsection{Convergence in Environmental Disclosure}

Convergence in reporting standards and in discourses of CDP participants and major carbonemitting firms facilitates transparency, comparability, and coordination. The standards and framing used in an arena can significantly impact firm operations and profits, as well as policy and political power. Carbon offset standards are an example of this (Gillenwater et al., 2007; Millard-Ball and Ortolano, 2010; Bushnell, 2010). Hawley and Williams (2005) make clear this link between corporate governance and environmental concerns in the CDP's framing of disclosure and fiduciary obligations more broadly.

The sizable literature on standard-setting organizations (SSOs) also relates to this research. While the CDP is not an SSO, its effectiveness in fostering disclosure and accountability relies in part on standardized disclosed information. Much of the standardization process and its value has been observed in the technology and communications industries (e.g., (Chiao et al., 2007; Schmalensee, 2009). SSOs can greatly impact investment decisions, firm coordination, and incentives to innovate, yet their policymaking process is less well understood. In the environmental arena, Boström and Hallström (2010) investigate power relations within global environmental SSOs and note how some nongovernmental organizations like the CDP face major difficulties in setting standards in a global, multi-stakeholder context. They suggest that organizational evolution should mitigate those difficulties over time, but fundamental mismatches between NGO operations and the standard-setting process will limit the emergence of standards -- even as the SSO still impacts partners.

According to institutional theory, rules and norms govern social behavior and shape interactions. Within this perspective, individuals or firm managers conform to the institutional symbols, rules, or regulations that they perceive to be external and objective (Cormier et al., 2005). The emergence of an institution produces social structures, rules, and routines that constrain individual actions. For an individual manager or organization, a safe way to justify an action is to imitate the practice of another organization that is widely believed or perceived to be a model (Cormier et al., 2005). This pressure is supported by socially acceptable beliefs and cultural frameworks. As firms attempt to conform to these beliefs and cultural frameworks, individual actions - such as environmental disclosure - become legitimized (Cormier et al., 2005).

Firms may also benefit from transparency through the process of collecting information. Firms that implement environmental management systems are known to have improved compliance records and have improved environmental performance (Potoski and Prakash, 2005b; Potoski and Prakash, 2005a; Prakash and Potoski, 2006). As transparency becomes routine, it may become self-reinforcing, as well.

A role of transparency may be to help disseminate improved management behavior, especially in areas that are not seen as core strategic activities by firms (Lyon and Maxwell, 2007). According to Lyon and Maxwell (2004), firms participate in voluntary environmental agreements in order to deflect the enactment or enforcement of more costly, mandatory regulation. The sponsor of the 
program, however, has incentive to disseminate best practices across participating and nonparticipating firms, in order to improve environmental behavior. These best practices may disseminate even without the explicit intervention of government, due to industry laggards imitating industry leaders (Lange, 2009). Because energy efficiency is frequently not seen as a core strategic activity, firms do not object to the dissemination of these practices (Lyon and Maxwell, 2007). Supporting this hypothesis, a study on the convergence of human resources management across international firms suggested that imitation of best practices was more common in "non-strategic" areas, such as human resources management, as opposed to finance and strategy (Carr and Pudelko, 2006).

Several studies have attempted to examine the convergence in reporting behavior and the content and standardization of disclosed information. It remains unclear whether environmental disclosure has increased over time, and whether firms have converged on specific reporting practices or standards. Considerable variation exists regarding reporting, the use of third-party assurance, and the content disclosed in corporate sustainability reports (Chen and Bouvain, 2009; Kolk, 2008; Kolk and Perego, 2010). Kolk (2005) finds that, despite trends of increasing transparency and reporting, firms have diverged in reporting practices and standards. In contrast, Cormier, et al. (2005) do not find increasing disclosure yet find within-industry convergence regarding the types of information disclosed. Brammer and Pavelin (2008) suggest that while convergence within industry is common, nearly all variation across firms is attributable to differences across industries. Nevertheless, inconsistent measurement techniques and standards, spotty verification practices, and a widely varying lexicon make the assessment of environmental reporting difficult.

Due to globalization and the rise of the 'global stateless firm', it is unclear the extent to which firms conform to international standards that are common across countries, or whether national standards, laws, and institutions are more likely to dictate corporate transparency. Kolk (2005) finds increasing regionalization of reporting practices amont firms that produce an environmental report.

\subsection{The increasing role of Scope 2 and Scope 3 emissions}

Greenhouse gas emissions are measured as either direct or indirect. Direct emissions are emitted from sources immediately controlled or owned by the reporting firm, and indirect emissions originate from an external source as a result of the reporting firm's actions (WBSCD/WRI, 2011). Scope 1 emissions are equivalent to direct emissions, and indirect emissions are divided into Scope 2 and Scope 3 (WBSCD/WRI, 2004). While direct emissions have received most attention from government, carbon footprints, which include Scope 2 (indirect emissions from electricity use) and Scope 3 (emissions from product lifecycle, supply chain, and distribution), have received increasing attention in both technical and policy literature (Piecyk, 2010; Prakash, 2002)

Scope 3 greenhouse gas emissions are indirect greenhouse gas emissions that cannot be classified as Scope 1 or Scope 2. In CDP surveys, commonly listed sources of Scope 3 emissions are "Business Travel”, “External Distribution”, “Use and Disposal of Products”, and "Company Supply Chain”. In emissions reporting schemes, Scope 3 is often listed as an optional complement to the mandatory Scope 1 and Scope 2 emissions (Huang et al., 2009; WBCSD/WRI, 2001; WBSCD/WRI, 2004). 
Scope 2 and Scope 3 emissions may dwarf a firm's direct emissions, accounting for as much as $75 \%$ of a firm's carbon footprint, and the types of Scope 3 emissions that are important vary greatly by industry (Huang et al., 2009). While Scope 2 and 3 emissions may be bigger than a firm's direct emissions, accounting procedures and standards remain highly variable and uncertain for these classes of emissions (Huang et al., 2009; Piecyk, 2010; Kolk et al., 2008). Research addressing Scope 2 and Scope 3 emissions have focused on two lines of research: how to calculate Scope 2 and Scope 3 emissions for a firm, industry, or geographical location (e.g. (Kennedy et al., 2010; Gentil et al., 2009; Larsen and Hertwich, 2009; Stolaroff et al., 2009; Piecyk, 2010), and whether or not firms are accounting for these emissions (Kolk et al., 2008).

To date, most research on the Carbon Disclosure Project has focused on its role in facilitating the disclosure of carbon strategies and direct emissions or simply whether firms choose to participate or not (e.g. (Kolk and Pinske, 2005; Kolk et al., 2008; Lyon and Kim, 2011). While Kolk, et al. (2008) found that the CDP has generated increasing responses over time, the quality of responses was highly variable. They find that, although Scope 2 emissions tend to be reported in congruence with direct emissions, by 2007 both the quantity and quality of Scope 3 emissions reporting remained highly discretionary. Further, they note an array of competing standards and protocols used to account for Scope 3 emissions, such as the UK Department of for Environment, Food, and Rural Affairs (DEFRA), the Intergovernmental Panel on Climate Change (IPCC), EPA Climate Leaders GHG Inventory Guidance, the International Petroleum Industry Environmental Conservation Association (IPECA), and the American Petroleum Institute (API), that complicates the comparability of any reported numbers. Kolk et al. (2008) note that some firms, such as the German utility E.ON, use different protocols and accounting standards in different countries. This heterogeneity of reporting demonstrates that carbon commensuration is not just a technical exercise, but a social and political process.

\subsection{Research contributions}

This research builds on earlier work on environmental reporting, carbon disclosure, and the CDP that has found significant variation in individual firm behavior (Sullivan, 2009) and variation in the quality of reporting and verification procedures (Cerin, 2002; Fonseca, 2010). Numerous researchers have called for research that assesses the impacts of global reporting standards and the use of text analytics software as a more reliable method of analyzing content than word counts or investigator coding, and work that "examines the quality of assurance statements, rather than merely their adoption" (Kolk and Perego, 2010). Further, other researchers have bemoaned the lack of longitudinal assessments conducted (Brammer and Pavelin, 2006; Brammer and Pavelin, 2008).

We go further than existing research by taking advantage of CDP data to uncover the extent to which environmental behavior by firms has converged in the area of climate change. Further, we use quantitative methods to measure the extent to which the discourse and lexicon about carbon management has converged among major corporations. In contrast to existing research that largely employs dichotomous measurements (e.g. (Peters and Romi, 2010; Kolk, 2005; Kolk, 2008; Kolk and Perego, 2010), we move beyond simple dichotomous indicators of disclosure by focusing on the types and quality of information disclosed. In contrast to cross-sectional data or two- or three-period data (e.g. (Brammer and Pavelin, 2006; Brammer and Pavelin, 2008; Kolk, 2005; Kolk, 2008; Kolk et al., 2008; Kolk and Perego, 2010), we take advantage of a longitudinal panel from 2003 - 2010. Additionally, in contrast to using coding mechanisms that 
rely on subjective measurements of disclosure behavior (e.g. (Cormier and Magnan, 2003;

Cormier et al., 2005), we employ text analytics, similar to Chen and Bouvain (2009), in order to achieve a great deal of standardization in the content analysis and to allow us to assemble a larger sample of firms over many years. This approach allows us to draw substantive conclusions about carbon management and the standardization of measurement and management techniques across firms, both within and across industry, and to observe changes in the implementation of carbon management.

\section{Greenhouse Gas Reporting Standards}

Responding firms report several greenhouse gas accounting methodologies in their responses. Appendix A describes several of these standards' important characteristics. We highlight four here: WBSCD/WRI Greenhouse Gas Protocol, ISO standards, IPCC, and DEFRA.

Developed in collaboration with multiple private, public, and non-governmental organizations, the World Business Council for Sustainable Development/ World Resources Institute (WBSCD/WRI) Greenhouse Gas Protocol is the most commonly listed response in all four years. It is distinguished by its universality and adaptability to most industrial sectors and reporting goals, as well as its classification of greenhouse gases into the three "scopes."

Second, the International Standards Organization (ISO) publishes ISO 14064 for greenhouse gas accounting. Part 1 of ISO 14064, organizational-level GHG reporting, closely corresponds with the WRI GHG Protocol (Weng and Boehmer, 2006). However, the WRI GHG Protocol details how to account for GHG emissions and ISO 14064 sets a minimum standard without detailing specific methods (Wintergreen and Delaney, 2007).

Established in 1988 by World Meteorological Organization (WMO) and the United Nations Environment Programme (UNEP), the Intergovernmental Panel on Climate Change (IPCC) is a scientific agency responsible for publishing the 2006 IPCC Guidelines for National Greenhouse Gas Inventories. Along with other IPCC publications, countries use this publication to report to the United Nations Framework Convention on Climate Change (UNFCCC). It is published in five volumes with specific methodologies for four sectors: energy, industrial processes and product use, agriculture, forestry, and other land use, and waste (IPCC, 2006).

Fourth, the UK's Department for Environment, Food, and Rural Affairs (DEFRA) publishes the "Guidance on how to measure and report your greenhouse gas emissions." This publication intends to help UK organizations of all sizes measure, reduce, and set reduction targets for greenhouse gas emissions. It was designed to be comparable to various other standards, such as ISO 14064 and the Carbon Trust Standard. At a basic level, DEFRA recommends calculating GHG emissions by multiplying activity data by emissions factors (DEFRA, 2009).

\section{Research Design}

\subsection{Overview}

Beginning in 2003, the Carbon Disclosure Project (CDP), an investor-led non-profit, began surveying large firms regarding their carbon related risks and strategies. Since 2006, the survey has been distributed to a wide range of firms across numerous industries. This study explores the content and convergence of firm responses to the CDP over time through two primary techniques. 
First, we assess the content provided in firm responses to emissions disclosure by using text analysis software to determine whether a firm provided a numerical response to emissions information. These data are useful in demonstrating trends related to the disclosure of types of emissions. Second, we assess firm responses to open-ended questions about their emissions accounting standards and verification behavior. We use a Herfindahl-Hirschman Index (HHI) to demonstrate the concentration of common keywords in firm responses regarding emissions accounting methodology. We also track the frequency of numerous competing emissions reporting standards to assess the extent to which firms have converged on specific reporting techniques and standards and highlight the extent to which firms use similar methodologies over time.

\subsection{Data Description}

Since 2003, firms submit completed CDP surveys each year before May 31. The disclosed data usually come from one or two years prior to the survey deadline. Firms responding to the Carbon Disclosure Project were given the option of designating their responses as either publicly or privately accessible. Private responses are available exclusively to institutional investors. Only public responses were examined in this study. From 2003-2010, approximately 2,900 unique firms publicly responded to the survey. Table 1 below lists the responding firm counts for each year the survey was issued.

Responding firms from 2007-2010 represented eight sectors: consumer discretionary, consumer staples, energy, financials, health care, industrials, information technology, materials, telecommunications, and utilities. The sample includes industry leaders and other major firms worldwide.

<insert Table 1 about here>

\subsection{Assessing Convergence in Carbon Disclosure}

First, to assess the extent of convergence in firm responses, we analyze firms' responses over time to questions pertaining to Scope 1, Scope 2, and Scope 3 emissions, as well as a question pertaining to whether or not these responses were externally verified. Undertaking a longitudinal study of the panel was difficult, due to the changing survey format of the questions over time. (This might explain why many studies rely on binary measurements of whether or not a firm responded to the CDP.) From 2003 to 2006, Scope 1 and 2 emissions data were combined into a single question, and no external verification question existed for these years. Also, until 2007, the responses to the emission questions were in an open-ended, multi-paragraph response format. For 2007, 2008, and 2010, the Scope 3 emissions question was divided into separate questions based on the type of Scope 3 emissions. And from 2007 to 2010, questions became numerical response questions.

In order to solve this problem, the four questions are analyzed with text analytics software. We define several categories for understanding the types of information that firms provided in the survey to the detailed questions regarding Scope 1, 2, and 3 emissions. From 2003 - 2006, the number of firms responding to each question are tallied: "Numerical Responses", "WRI GHG Protocol”, and "Unanswered”. "Numerical Responses” refers to firms that used quantitative information in their answer. Our analysis counted any response that included a number as a 
"numerical response”, which also included responses that mentioned a year (e.g., "1999”)."WRI GHG Protocol” includes firms responding with keywords referencing the World Resources Institute's greenhouse gas protocol. "Unanswered" counts the firms that left the question entirely blank. For 2007 - 2010, the categories are “Numerical Responses” and "Unanswered”.

In the questions pertaining to external verification, firms selected their response from a dropdown list supplied by the CDP. For 2007 and 2008, the categories in the list were "Yes”, "No", and "Unanswered". In 2009, a category was added for the response, "No information provided in applicable questions", referring to firms that did not provide any information in the emissions questions. In 2010, the CDP divided responses according to the three emissions scopes. Seven categories exist for each scope: "Not Verified", "More than 0\%, but less than 20\%", "More than $20 \%$, but less than $40 \%$ ", "More than $40 \%$, but less than $60 \%$ ", More than $60 \%$, but less than 80\%", "More than 80\%, but less than 100\%", and "Unanswered". The number of firms included in each category is recorded. The percentage of firms responding to each category is calculated by dividing number of responding firms by the total firms for that year. Below, we discuss trends from 2003 to 2010 in the disclosure and verification of carbon emissions, shown in Table 2.

A second technique in measuring response convergence is the use of a Herfindahl-Hirschman Index (HHI). Originally, the HHI was developed to measure industrial concentration in markets (Hirschman, 1964). In this study, we employ the HHI to measure the concentration of the most frequently used keywords and phrases over time. Using the HHI, we determine whether the lexicon regarding climate change is converging based on changes in "market share" among terms used in reporting.

The keywords and phrases are generated from responses to questions in CDP2007-CDP2010 that inquired about the accounting methodology the firms used to manage their greenhouse gas emissions. The CDP inquired about the Scope 1 and Scope 2 emissions methodology separately from the Scope 3 emissions. For this study, we aggregate responses for Scope 1, 2, and 3 emissions. After responses are aggregated for each firm, the responses are analyzed with SPSS Text Analytics for Surveys (STAS) software. We identify the top 200 "null concept patterns” for each year. As defined by STAS, “concept patterns” are a combination of frequently occurring keywords and "type", a group of similar keywords. "Null concept patterns" (NCP) occur when a significant keyword occurs without the presence of a subsequent "type". A list of the overall top 200 NCPs is created by aggregating lists from 2007 - 2010. Of this list, the top 100 are retained for use in the HHI.

Typically, the HHI is calculated by summing the squares of the market share of every firm in a market. In this study, we analogously calculate the percentage share using each of the NCPs each year. Each of these yearly percentage shares are squared and summed to produce an annual HHI value. As lexicon concentration increases, the HHI score also increases. We expect that the HHI score will increase as the language used in firm responses to the CDP converges.

\section{Results}

We divide discussion of the results into two sections: 2003 - 2006, and 2007 - 2010, due to dramatic changes in the questionnaire and sample size. 


\section{3 - 2006 (See Table 2 below)}

Between 2003 and 2006, the total number of firms answering the survey and providing quantitative responses to Scope 1, 2, and 3 increased dramatically. However, the percentage of firms providing quantitative responses increased only moderately. The quality of responses, at least for Scope 1 and 2 emissions, improved. Between 2003 and 2006, both the number and the percentage of firms referencing the WRI Greenhouse Gas Protocol in their accounting methodology increased dramatically, while the number and percentage of firms skipping the question or leaving it blank decreased dramatically. From 2003 - 2006, the share of firms referencing the WRI GHG protocol for Scope 1 and 2 more than tripled, and the share skipping the emissions questions fell by two thirds. Interestingly, Scope 3 emissions did not follow a similar trend; Scope 3 emissions reporting remained flat.

$<<$ insert Table 2 about here $>>$

\section{7 - 2010 (see Tables 3 - 7 below)}

Between 2007 and 2010, a complex picture of trends in transparency emerges. Despite a gradually increasing sample size of firms releasing responses publicly, the number and percentage of firms providing quality information for Scope 1, Scope 2, and emissions from employee business travel (part of Scope 3) increases. In contrast, the percentage of firms providing quality lifecycle analysis or supply chain data does not increase (though the total number of firms providing these data increases).

When the overall trends in the public disclosure of data and industry and country / region trends are considered, a more pessimistic view of transparency emerges. Between 2007 and 2010, the vast majority of new firms providing responses to the CDP survey did not make their responses public (see Table 1). Despite the number of firms responding to the CDP more than doubling from 2007 to 2010 (from 1449 to 3050 firms), the share of responses that were public fell from $63.4 \%$ to $43.2 \%$.

Country and industry trends show similarly mixed patterns in transparency. Of firms providing a publicly available response, European Union based firms and Japanese firms have generally increased the quality of responses. U.S. firms, in contrast, increased the quality of responses through 2009, but in 2010 only 24.6 percent of firms provided numerical Scope 1 and Scope 2 data, in contrast to 58.4 percent in 2007 and 81.8 percent in 2009 (see Table 5). Industry trends reveal a mixed picture, as well as a lack of consistency. Materials, industrials, and information technology sectors have the largest gains of transparency - all with over 20 percent gains between 2007 and 2010. Energy firms and consumer staples remain highly transparent throughout the sample years. Financials, consumer discretionary, and utilities remain relatively unchanged, and telecommunications and healthcare sectors decrease their transparency (see Table 4).

Table 6 does not show a clear trend towards increased verification of emissions data between 2007 and 2010 among those firms providing publicly available responses. The changing question formats over time limits the analysis of verification trends. In 2010, the question changes to exclude firms that did not provide information in the first place and to allow for partial verification of emissions. In 2010, 44.4 percent, 38.4 percent, and 21.0 percent of firms report at least partial verification of Scope 1, 2, and 3 emissions, respectively. 
In order to determine whether there was a clear convergence of the discourse regarding carbon management and climate change, we examine our lexicon concentration measurement, which mimics the HHI methodology. We calculate the "market share" of each keyword based on the list of the top 100 keywords and phrases used by respondents in the accounting methodology sections of the CDP surveys. As demonstrated in Table 7, from 2007 to 2010, the market share of the top 100 keywords and phrases increased from 184 to 357. Corporate discourse regarding climate change has converged recently. That the concentration or convergence in lexicon increased despite more firms participating in the CDP indicates an especially strong trend.

In addition, we demonstrate the total share of firms reporting the use of a wide variety of standards and carbon accounting methodologies. As Table 8 shows, usage of the WBSCD / WRI protocol has increased from 45 percent in 2007 to 63 percent in 2010. More tellingly, however, the usage of the top four accounting methodologies has dominated the increase of use of accounting methodologies. WBSCD / WRI, IPCC, DEFRA, and ISO are the only standards to have garnered more than 10 percent of the total firms. Most of the other standards have failed to gain traction. Interestingly, only the top 5 standards, plus CCAR, received more than $1 \%$ market share and experienced a consistently increasing "market share" of standards use over time. Appendix B offers a comparison of several of these methodologies, and Appendix C and D give region and industry breakdowns of the standards, respectively..

$<$ <insert Table 3 about here >>

$<<$ insert Table 4 about here $>>$

$<$ <insert Table 5 about here $>>$

$<$ <insert Table 6 about here $>>$

$<<$ insert Table 7 about here $>>$

$<<$ insert Table 8 about here $>>$

\section{Discussion}

These results present a decidedly mixed perspective regarding the transparency of firms related to carbon management and accounting, supporting previous studies that found similar characteristics within a smaller sample (Sullivan, 2009). There are numerous signs of improved management by firms; there are also many signs that suggest that transparency gains achieved by the CDP in early years have failed to produce a lasting trend towards transparency. Responses from CDP participants in more recent years are overwhelmingly private, rather than publicly disclosed. There is little evidence that firms have increased external verification, and in the U.S. the quality of emissions reporting decreased substantially in 2010 (perhaps in response to reduced political expectations of carbon regulation). These results are similar to other studies that suggest wide variation in assurance and verification quality (Fonseca, 2010; Cerin, 2002). Firms that have large Scope 1 and Scope 2 carbon footprints including materials, industrials, energy firms, and consumer staples have been most likely to disclose carbon-related data. Industries without large direct carbon impacts - such as hospitals, financials, and telecommunications, have been less forthcoming with data, consistent with theory suggesting that firms that have the most carbon related regulatory risk ought to be the most likely to disclose data (Brammer and Pavelin, 2006). However, the largest emitters of all, utilities, continue to remain relatively opaque. 
Among firms making their responses public, firms have been increasingly likely to employ a standardized accounting methodology and report numerical data in response to Scope 1, 2, and 3 emissions queries. This suggests that firms are paying closer attention to carbon management. Improved information is certainly a step towards improved management. It is unclear, however, whether increased transparency and better data are the result of the Carbon Disclosure Project, or are simply reflecting broader changes in carbon management. It is possible that by asking firms to report certain information, firm managers begin to collect that information. This hypothesis is supported by data in 2005 and 2009, where large spikes of transparency are reported the year after the year of a big expansion of the sample size. Even though CDP participants may not know the answer to new reporting questions upon first encountering them, they learn fast and response rates are much higher the next time around.

For example, between 2003 and 2004, the number of firms increased more than 50 percent, from 146 to 226 firms. This dramatic increase happened again between 2005 and 2006 (and again in 2007). In 2005, however, when the number of firms increased only slightly over 2004, 80.8 percent of firms provided quantitative responses to Scope 3 emissions, up from 49 percent in 2004. Only two (four) firms did not answer Scope 1 and 2 emissions (Scope 3 emissions), down from roughly double that number in the prior year. In 2009, another year where the sample size had not increased (it actually decreased), the response to Scope 1 emissions jumped from 53.8 percent in 2008 to 74.8 percent in 2009 . Scope 2 emissions reporting jumped from 49.3 percent in 2008 to 71.3 percent in 2009. Thus, in the year after a spike in sample size, larger spikes in transparency appear.

The increase of transparency related to Scope 1 emissions is unsurprising. Mandatory regulations in Europe, Japan, Australia and many U.S. states have forced firms to at least report, if not control, Scope 1 emissions. In the EU, where a cap-and-trade program has been implemented through the European Union Emissions Trading Scheme, most firms must control but do not have to disclose direct emissions publicly. Yet, even there, Scope 1 emissions reporting rates far exceed the US level.

More interestingly, reporting of Scope 2 emissions has burgeoned, and Scope 3 emissions has increased in some areas, while in others has remained relatively stable (again, suggesting an increase in the number of firms reporting, but a constant percentage). These trends suggest a more important role for the Carbon Disclosure Project. In 2007, 48.6 percent of firms reported indirect emissions, which includes electricity usage. By 2010, 67.6 percent of firms reported indirect emissions. Trends in Scope 3 emissions reporting have been more mixed. In 2007, 17.8 percent of firms reported emissions from business travel, increasing to 44.2 percent in 2010 . The percentage of firms reporting distribution-related emissions increased by 3 percentage points, from 9.7 percent to 12.8 percent. Again, because these numbers are percentages of an increasing sample size, they mask the increase in the total number of firms reporting this sustainability data publicly.

Scope 2 and Scope 3 emissions speak to a broader sustainability role for carbon management. Because electricity use and fuel use are frequently substitutes and the product life cycle, supply chain, business travel, and distribution of products may have a much bigger carbon footprint than the direct emissions of a firm, these measurements provide important information to stakeholders and shareholders about the firm's carbon-related activities. The increase in reporting is an important sign that, at the very least, firms are beginning to pay attention to their carbon footprint, 
are defining their carbon footprint in a much broader sense than just direct emissions, and are thus considering how they might be able to manage their carbon footprint better.

The results from the HHI calculation of keyword and phrase concentration by firms points towards a convergence of management language. The types of keywords and phrases in this analysis generally refer to management techniques, measurement techniques, and reporting standards. The top 100 keywords and phrases were much more common in 2010 than they were in 2007, suggesting that the lexicon is becoming more standardized, and firms have moved towards similar measurement and reporting standards. This is supported, in part, by the increased use of the World Resources Institute Greenhouse Gas Protocol between 2003 and 2006 for Scope 1 and 2 emissions, and by the presence of the WRI GHG protocol as one of the top keywords between 2007 and 2010. Other standards and protocols received significant attention between 2007 and 2010, such as the IPCC, the DEFRA standards, and the ISO standards. This indicates that there might be institutional, regional, or industrial convergence towards competing standards. Regardless (and perhaps more importantly from a carbon management perspective), these “competing” standards may not be all that competing. The DEFRA and ISO standards are designed to be relatively compatible with the WBSCD / WRI guidelines, which, in turn, were developed to be compatible with the IPCC guidelines. As these standards gain traction, it ought to make carbon management more transparent and bolster stakeholder faith in the numbers that are reported to the CDP.

Nevertheless, we were hampered by a CDP survey that changed nearly each and every year, as well as a changing sample. The CDP changed the types of information they were requesting over time, as well as the format in which the questions were asked. Sometimes, they provided dropdown menus. Sometimes, they dropped questions. In 2009, for example, the CDP did not ask, specifically, about Scope 3 emissions. Many times, they added questions or attempted to extract more specific information from investors.

On one hand, the changes in the CDP format often seemed reasonable. They have increasingly moved from open-ended responses, where firms often appear to cut and paste large amounts of (often irrelevant) information, to multiple choice answers that force firms to provide specific types and formats of answers. They have seemed to adapt to circumstances where firms were providing irrelevant information by structuring the questions differently and by asking for more specific types of information.

On the other hand, shifting the questions each and every year greatly complicates tracking data over time. Considering the time, effort, and sophisticated text analytics necessary just to extract comparable information across years (exclusive of time and expertise in analyzing it) at least calls into question the purpose of the CDP's disclosure or transparency program (Bae et al., 2010). We had to align questions across years, and, even then, we still had to omit 2009 from part of the analysis, and 2003 - 2006 is not comparable to 2007 - 2010. This discord is evident in some of the survey responses themselves. While most firms have improved their responses over time, the changing nature of the survey seems to undermine the responses of others. Caterpillar, for example, provided very specific and detailed information early on in the survey, but in later years provided a nearly irrelevant corporate sustainability statement. Because firms are frequently graded on whether or not they respond to a question rather than the quality of their responses (partly due to the lack of standardization in the survey), and because responses may not be particularly useful to investors or researchers, there may be insufficient motivation to provide detailed information to the CDP. 


\section{Conclusions and directions for further research}

In contrast to much existing research, this research engages in a longitudinal study of corporate transparency data and takes into account the quality of firm responses. This research makes advances in both the quantity and quality of information assessed related to very specific disclosures of carbon related activities.

The trend towards keeping responses private, rather than public, is potentially alarming from a perspective that sees transparency as a key to improved management. It also raises many questions regarding the quality of private responses versus those released publicly, as well as the potential impact on firms from awareness in the broader public, versus the impact from institutional investors.

If firms are graded simply on whether or not they answer a question, rather than the quality of their responses, firms will likely avoid the disclosure of quality information. The reasons behind the enormous and recent drop-off in quality responses from US firms are unclear. On one hand, firms may have anticipated changes in the political environment, leading them to strategically avoid disclosure. On the other, the Securities and Exchange Commission (SEC) has begun requiring a similar, but mandatory, disclosure, perhaps making the CDP obsolete. It is unclear the extent to which the SEC guidelines will mimic the CDP efforts. Similarly, mandatory reporting requirements in part of the EU ETS may obviate the need for a voluntary reporting database for Scope 1 emissions.

These developments suggest a tradeoff between voluntary and mandatory reporting regimes. While mandatory reporting requirements may be an effective way to force disclosure of direct emissions, voluntary disclosure program like the CDP may allow firms to engage with stakeholders such as investors and employees more directly than mandatory reporting requirements and serve as a way to improve internal management of greenhouse gases (Stanny and Ely, 2008).

The decrease in transparency by U.S. firms in 2010 raises many questions regarding the viability of a voluntary disclosure program. If firms participate in a voluntary program to deflect the enactment or enforcement of a more stringent mandatory program (Lyon and Maxwell, 2004), the success of a voluntary program is at best a second-best solution that is dependent upon political pressure for more stringent mandatory programs.

However, by encouraging voluntary reporting and disclosure, the CDP gives firms a way to distinguish themselves from competitors and gain recognition for going beyond compliance. In contrast, participation in a mandatory reporting environment, such as the EU ETS (which does not make direct emissions public), reduces incentives for moving beyond compliance. In addition, the CDP has a unique role in promoting the disclosure of Scope 2 and Scope 3 emissions, which are unlikely to be addressed through mandatory regulation or disclosure rules.

Finally, the CDP - as well as other efforts to encourage greenhouse gas reporting and verification - have helped establish norms for carbon accounting methodology. Some of the strongest evidence for convergence in this study related to the specific standards employed for carbon accounting methodology. That firms have converged to use specific methods for carbon accounting, without the coercive force of government demonstrates an important role for voluntary initiatives like the CDP in achieving consensus regarding reporting standards. The 
learning proces by participating firms seems especially promising, as reporting imporves soon after joining.

Nevertheless, the complexity and changes to the CDP survey have made it particularly difficult to assess CDP responses, despite the rich information collected by the organization. A voluntary disclosure program, unlike a mandatory one, might allow for less uniformity and standardization and hamper comparability over time and across firms. (In contrast, the freedom afforded firms in reporting through the CDP allows us to observe the 'natural' convergence in reporting in a voluntary system.) We acknowledge that the CDP is attempting to improve their methodology and assessment techniques. The CDP has begun to grade firms based on the content of their responses, though too frequently this is still conducted as a binary measurement based on whether a firm has provided information in response to a question. More attention needs to be directed towards generating a survey and response system that is consistent over time and collects more usable information.

Due to our focus on improving the types of information gathered from the CDP survey and the challenges in extracting that information, we have not begun to parse patterns in the responses or the non-responses. Future research should seek to assess how individual firms change their responses over time and which firms withhold information. We can assess which types of firms are converging on different standards, and correlate the content of responses with shareholder value or measurements of observed environmental performance. Significant uncertainty remains regarding whether reporting and verification reflects actual firm behavior (Kolk and Pinkse, 2010; Fonseca, 2010), or whether it is simply an exercise in public relations (Cerin, 2002). Recent findings suggest that improved disclosure and management are correlated with higher toxic releases and lower environmental compliance (Delmas and Blass, 2010), suggesting that improved disclosures may not correlate with improved environmental performance.

We demonstrate a mixed trend towards increasing disclosure and increased transparency, with some areas - especially in the area of unregulated Scope 2 activity - suggesting improvements in transparency. Other areas - including the verification of disclosed information - suggest a lack of improvement. There is some convergence in specific accounting methodologies. This research contributes to previous findings that do not demonstrate increasing transparency over time, and contributes to the convergence / divergence debate. While on the whole we demonstrate convergence in the types of information supplied and the lexicon used by firms that make their responses publicly available, future research should seek to further parse convergence patterns.

\section{References}

AccountAbility. 2008. AA1000 Assurance Standard 2008. AccountAbility.

AUASB. 2007. Standard on Assurance Engagements ASAE 3000 Assurance Engagements Other than Audits or Reviews of Historical Financial Information

Bae, H., Wilcoxen, P. J. and Popp, D. 2010. Information Disclosure Policy: Do State Data Processing Efforts Help More than the Information Disclosure Itself. Journal of Policy Analysis and Management, 29: 163-82.

Barber, B. M. 2007. Monitoring the Monitor: Evaluating CalPERS' Activism. Journal of Investing, 16: 66-80. 
Berry, W. D. 1984. An Alternative to the Capture Theory of Regulation: The Case of State Public Utility Commissions. American Journal of Political Science, 28: 524-58.

Berthelot, S., Cormier, D. and Magnan, M. 2003. Environmental Disclosure Research: Review and Synthesis. Journal of Accounting Literature, 22: 1-44.

Blacconiere, W. G. and Patten, D. M. 1994. Environmental disclosures, regulatory costs, and changes in firm value. Journal of Accounting and Economics, 18: 357-77. DOI: 10.1016/01654101(94)90026-4.

Boström, M. and Hallström, K. T. 2010. NGO Power in Global Social and Environmental StandardSetting. Global environmental politics, 10: 36-59. DOI: 10.1162/GLEP_a_00030.

Botosan, C. A. 1997. Disclosure Level and the Cost of Equity Capital. The Accounting Review, 72: 32349.

Brammer, S. and Pavelin, S. 2006. Voluntary Environmental Disclosures by Large UK Companies. Journal of Business Finance \& Accounting, 33: 1168-88. DOI: 10.1111/j.14685957.2006.00598.x.

Brammer, S. and Pavelin, S. 2008. Factors influencing the quality of corporate environmental disclosure. Business Strategy and The Environment, 17: 120-36. DOI: 10.1002/bse.506.

Bushnell, J. B. 2010. The Economics of Carbon Offsets. National Bureau of Economic Research, Inc.

California Climate Action Registry. 2011. "Overview". 2011. Climate Registry. 20 January 2012. $<$ http://www.climateregistry.org/about.html\%3E.

Carbon Trust. 2011. "The Carbon Trust Standard". 2011. 1 September 2011. $<$ http://www.carbontruststandard.com/pages/The-Standard\%3E.

Carr, C. and Pudelko, M. 2006. Convergence of Management Practices in Strategy, Finance and HRM between the USA, Japan and Germany. International Journal of Cross Cultural Management, 6: 75-100. DOI: 10.1177/1470595806062353.

Cerin, P. 2002. Communication in corporate environmental reports. Corporate Social Responsibility and Environmental Management, 9: 46-65. DOI: 10.1002/csr.6.

Chen, S. and Bouvain, P. 2009. Is Corporate Responsibility Converging? A Comparison of Corporate Responsibility Reporting in the USA, UK, Australia, and Germany. Journal of Business Ethics, 87: 299-317. DOI: 10.1007/s10551-008-9794-0.

Chiao, B., Lerner, J. and Tirole, J. 2007. The rules of standard-setting organizations: an empirical analysis. The RAND Journal of Economics, 38: 905-30. DOI: 10.1111/j.0741-6261.2007.00118.x.

Chicago Climate Exchange. 2011. "Ice OTC: Chicago Climate Exchange". 2011. 20 January 2012. $<$ https://http://www.theice.com/ccx.jhtml\%3E.

Cormier, D. and Magnan, M. 2003. Environmental reporting management: a continental European perspective. Journal of Accounting and Public Policy, 22: 43-62. DOI: 10.1016/s02784254(02)00085-6.

Cormier, D., Magnan, M. and Van Velthoven, B. 2005. Environmental disclosure quality in large German companies: Economic incentives, public pressures or institutional conditions? European Accounting Review, 14: 3-39. DOI: 10.1080/0963818042000339617.

DEFRA. 2009. Guidance on how to measure and report your greenhouse gas emissions.

Delmas, M. and Blass, V. D. 2010. Measuring corporate environmental performance: the trade-offs of sustainability ratings. Business Strategy and The Environment, 19: 245-60. DOI: 10.1002/bse.676.

Environmental Protection Agency. 2011. Basic Information. http://www.epa.gov/climateleaders/basic/index.html.

EPA. 2012. "Basic Information: Environmental Management Systems". 2012. (27 July 2011): EPA. 20 January 2012. <http://www.epa.gov/epawaste/inforesources/ems/basic.htm\%3E.

European Commission. 2009. "The EU Emissions Trading Scheme." 28 pp. $<$ http://ec.europa.eu/clima/publications/docs/ets en.pdf\%3E.

Fonseca, A. 2010. How credible are mining corporations' sustainability reports? a critical analysis of external assurance under the requirements of the international council on mining and metals. 
Corporate Social Responsibility and Environmental Management, 17: 355-70. DOI:

10.1002/csr.230.

Gentil, E., Christensen, T. H. and Aoustin, E. 2009. Greenhouse gas accounting and waste management. Waste Management \& Research, 27: 696-706. DOI: 10.1177/0734242x09346702.

Gillenwater, M., Broekhoff, D., Trexler, M., Hyman, J. and Fowler, R. 2007. Policing the voluntary carbon market. 85-87.

Global Reporting Initiative. 2011. G3.1 Guidelines incl. Technical Protocol.

Gronewold, N. January 3, 2011. "Chicago Climate Exchange Closes Nation's First Cap-And-Trade System but Keeps Eye to the Future." New York Times.

Haddock-Fraser, J. and Fraser, I. 2008. Assessing corporate environmental reporting motivations: differences between 'close-to-market' and 'business-to-business' companies. Corporate Social

Responsibility and Environmental Management, 15: 140-55. DOI: 10.1002/csr.147.

Hawley, J. P. and Williams, A. T. 2005. Shifting ground: emerging global corporate-governance standards and the rise of fiduciary capitalism. Environment and Planning A, 37: 1995-2013.

Hirschman, A. O. 1964. The Paternity of an Index. American Economic Review, 54: 761.

Hoffman, V. 2007. EU ETS and Investment Decisions: The Case of The German Electricity Industry. European Management Journal, 25: 464-74.

Huang, Y. A., Weber, C. L. and Matthews, H. S. 2009. Categorization of Scope 3 Emissions for Streamlined Enterprise Carbon Footprinting. Environmental Science \& Technology, 43: 8509-15. DOI: 10.1021/es901643a.

IAASB. 2008. ISAE 3000, Assurance Engagements Other Than Audits or Reviews of Historical Financial Information New York: International Federation of Accountants.

Intergovernmental Panel on Climate Change. 2011. "Organization". 2011. 20 January 2012. $<$ http://www.ipcc.ch/organization/organization.shtml\%3E.

IPCC. 2006. 2006 IPCC Guidelines for National Greenhouse Gas Inventories.

ISO. 2011. "About ISO ". 2011. <http://www.iso.org/iso/about.htm\%3E.

Kennedy, C., Steinberger, J., Gasson, B., Hansen, Y., Hillman, T., Havrnek, M., Pataki, D., Phdungsilp, A., Ramaswami, A. and Mendez, G. V. 2010. Methodology for inventorying greenhouse gas emissions from global cities. Energy Policy, 38: 4828-37. DOI: 10.1016/j.enpol.2009.08.050.

Knox-Hayes, J. and Levy, D. L. 2011. The politics of carbon disclosure as climate governance. Strategic Organization, 9: 91-99. DOI: 10.1177/1476127010395066.

Kolk, A. 2005. Environmental Reporting by Multinationals from the Triad: Convergence or Divergence? Management International Review, 45: 145-66.

Kolk, A. 2008. Sustainability, accountability and corporate governance: exploring multinationals' reporting practices. Business Strategy and The Environment, 17: 1-15. DOI: 10.1002/bse.511.

Kolk, A., Levy, D. and Pinske, J. 2008. Corporate responses in an emerging climate regime: The institutionalization and commensuration of carbon disclosure. European Accounting Review, 17: 719-45.

Kolk, A. and Perego, P. 2010. Determinants of the adoption of sustainability assurance statements: an international investigation. Business Strategy and The Environment, 19: 182-98. DOI: 10.1002/bse.643.

Kolk, A. and Pinkse, J. 2010. The integration of corporate governance in corporate social responsibility disclosures. Corporate Social Responsibility and Environmental Management, 17: 15-26. DOI: 10.1002/csr.196.

Kolk, A. and Pinske, J. 2004. Market Strategies for Climate Change. European Management Journal, 22: 304-14.

Kolk, A. and Pinske, J. 2005. Business Responses to Climate Change: Identifying Emergent Strategies. California Management Review, 47

Lange, I. 2009. Evaluating Voluntary Measures with Treatment Spillovers: The Case of Coal Combustion Products Partnership. The B.E. Journal of Economic Analysis \& Policy, 9 
Larsen, H. N. and Hertwich, E. G. 2009. The case for consumption-based accounting of greenhouse gas emissions to promote local climate action. Environmental Science \&amp; Policy, 12: 791-98. DOI: 10.1016/j.envsci.2009.07.010.

Lev, B. 1992. Information Disclosure Strategy. California Management Review, 34: 9-32.

Li, Y. U. E., Richardson, G. D. and Thornton, D. B. 1997. Corporate Disclosure of Environmental Liability Information: Theory and Evidence*. Contemporary Accounting Research, 14: 435-74. DOI: 10.1111/j.1911-3846.1997.tb00535.x.

Lyon, T. P. and Kim, E.-H. 2011. When Does Institutional Investor Activism Increase Shareholder Value?: The Carbon Disclosure Project. The B.E. Journal of Economic Analysis \& Policy, 11

Lyon, T. P. and Maxwell, J. W. 2004. Corporate Environmentalism and Public Policy, Cambridge, U.K.: Cambridge University Press.

Lyon, T. P. and Maxwell, J. W. 2007. Environmental Public Voluntary Programs Reconsidered. Policy Studies Journal, 35: 723-50.

McCarthy, G. 2010. Partners Letter. Environmental Protection Agency.

Millard-Ball, A. and Ortolano, L. 2010. Constructing carbon offsets: The obstacles to quantifying emission reductions. Energy Policy, 38: 533-46. DOI: 10.1016/j.enpol.2009.10.005.

Peters, G. and Romi, A. 2010. Carbon Emission Accounting and Disclosure: An International Empirical Investigation. Unpublished Working paper. University of Arkansas.

Piecyk, M. 2010. Carbon auditing of companies, supply chains, and products, in A. C. McKinnon, S. Cullinane, M. Browne and A. Whiteing, (eds): Green Logistics: Improving the Environmental Sustainability of Logistics. London: Kogan Page Limited.

Potoski, M. and Prakash, A. 2005a. Covenants with weak swords: ISO 14001 and facilities' environmental performance. Journal of Policy Analysis and Management, 24: 745-69.

Potoski, M. and Prakash, A. 2005b. Green Clubs and Voluntary Governance: ISO 14001 and Firms' Regulatory Compliance. American Journal of Political Science, 49: 235-48.

Prado-Lorenzo, J. M., Rodríguez-Domínguez, L., Gallego-Álvarez, I. and García-Sánchez, I. M. 2009. Factors influencing the disclosure of greenhouse gas emissions in companies world-wide. Management Decision, 47: 1133-57.

Prakash, A. 2002. Green marketing, public policy and managerial strategies. Business Strategy and The Environment, 11: 285-97. DOI: 10.1002/bse.338.

Prakash, A. and Potoski, M. 2006. The Voluntary Environmentalists: Green Clubs, ISO 14001, and Voluntary Environmental Regulations, Cambridge, United Kingdom: Cambridge University Press.

Reid, E. M. and Toffel, M. W. 2009. Responding to public and private politics: corporate disclosure of climate change strategies. Strategic Management Journal, 30: 1157-78. DOI: 10.1002/smj.796.

Schmalensee, R. 2009. Standard-Setting, Innovation Specialists and Competition Policy. The Journal of Industrial Economics, 57: 526-52. DOI: 10.1111/j.1467-6451.2009.00388.x.

Skinner, D. J. 1994. Why Firms Voluntarily Disclose Bad News. Journal of Accounting Research, 32: 3860.

Spence, C. 2009. Social and environmental reporting and the corporate ego. Business Strategy and The Environment, 18: 254-65. DOI: 10.1002/bse.600.

Stanny, E. and Ely, K. 2008. Corporate environmental disclosures about the effects of climate change. Corporate Social Responsibility and Environmental Management, 15: 338-48. DOI: 10.1002/csr.175.

Stiller, Y. and Daub, C.-H. 2007. Paving the way for sustainability communication: evidence from a Swiss study. Business Strategy and The Environment, 16: 474-86. DOI: 10.1002/bse.599.

Stolaroff, J. K., Weber, C. L. and Scott Matthews, H. 2009. Design issues in a mandatory greenhouse gas emissions registry for the United States. Energy Policy, 37: 3463-66. DOI: 10.1016/j.enpol.2009.04.028.

Sullivan, R. 2009. The management of greenhouse gas emissions in large European companies. Corporate Social Responsibility and Environmental Management, 16: 301-09. DOI: 10.1002/csr.187. 
Walker, B. and Salt, D. 2006. Resilience Thinking: sustaining ecosystems and people in a changing world, Washington, D.C.: Island Press.

WBCSD/WRI. 2001. The Greenhouse Gas Protocol. Geneva: World Business Council for Sustainable Development and World Resources Institute.

WBSCD/WRI. 2004. The Greenhouse Gas Protocol. Geneva: World Business Council for Sustainable Development and World Resources.

WBSCD/WRI. 2011. Corporate Value Chain (Scope 3) Accounting and Reporting Standard. Geneva: The Greenhouse Gas Protocol.

Weng, C. K. and Boehmer, K. 2006. Launching of ISO 14064 for greenhouse gas accounting and verification. ISO Management Systems.

Wintergreen, J. and Delaney, T. 2007. ISO 14064, International Standard for GHG Emissions Inventories and Verification. Raleigh, NC: 16th Annual International Emissions Inventory Conference. 
Table 1: Firm Counts in Carbon Disclosure Project Sample by Year

\begin{tabular}{|l|l|l|l|l|l|l|l|l|}
\hline CDP Year & $\mathbf{2 0 0 3}$ & $\mathbf{2 0 0 4}$ & $\mathbf{2 0 0 5}$ & $\mathbf{2 0 0 6}$ & $\mathbf{2 0 0 7}$ & $\mathbf{2 0 0 8}$ & $\mathbf{2 0 0 9}$ & $\mathbf{2 0 1 0}$ \\
\hline $\begin{array}{l}\text { Public } \\
\text { Firms }\end{array}$ & 146 & 226 & 265 & 588 & 952 & 1061 & 1247 & 1513 \\
\hline $\begin{array}{l}\text { Total } \\
\text { Respondents }\end{array}$ & 221 & 295 & 355 & 922 & 1300 & 1538 & 1849 & 2049 \\
\hline $\begin{array}{l}\text { Targeted } \\
\text { Firms }\end{array}$ & 501 & 501 & 500 & 2166 & 2444 & 3055 & 3741 & 4792 \\
\hline $\begin{array}{l}\text { Percent of } \\
\text { Targeted } \\
\text { Firms } \\
\text { Responding }\end{array}$ & $44.1 \%$ & $58.9 \%$ & $71.0 \%$ & $42.5 \%$ & $53.2 \%$ & $50.3 \%$ & $49.4 \%$ & $42.7 \%$ \\
\hline $\begin{array}{l}\text { Percent of } \\
\text { Targeted } \\
\text { Firms } \\
\text { Responding } \\
\text { Publicly }\end{array}$ & $29.1 \%$ & $45.1 \%$ & $53.0 \%$ & $27.1 \%$ & $38.9 \%$ & $34.7 \%$ & $33.3 \%$ & $31.6 \%$ \\
\hline $\begin{array}{l}\text { Annual } \\
\text { Investors } \\
\text { (Firm } \\
\text { Count) }\end{array}$ & 35 & 95 & 155 & 225 & 315 & 385 & 475 & 534 \\
\hline $\begin{array}{l}\text { Combined } \\
\text { Investor } \\
\text { Assets } \\
\text { trillions of } \\
\text { USD) }\end{array}$ & 4.5 & 10 & 21 & 31.5 & 41 & 57 & 55 & 64 \\
\hline
\end{tabular}


Table 2: Disclosure to the CDP: 2003 - 2006

\begin{tabular}{|c|c|c|c|c|c|}
\hline & & 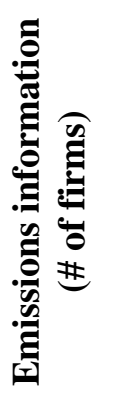 & 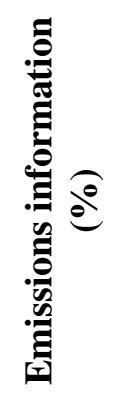 & 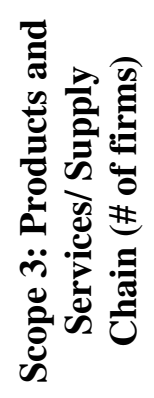 & 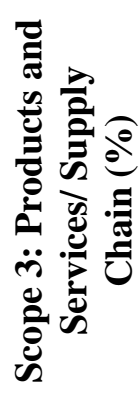 \\
\hline \multirow{3}{*}{$\begin{array}{l}\text { CDP } \\
2003\end{array}$} & Numerical Response & 99 & $67.8 \%$ & 72 & $49.3 \%$ \\
\hline & WRI GHG Protocol & 11 & $7.5 \%$ & 4 & $2.7 \%$ \\
\hline & Unanswered & 21 & $14.4 \%$ & 21 & $14.4 \%$ \\
\hline \multirow{3}{*}{$\begin{array}{l}\text { CDP } \\
2004\end{array}$} & Numerical Response & 180 & $79.6 \%$ & 110 & $48.7 \%$ \\
\hline & WRI GHG Protocol & 36 & $15.9 \%$ & 9 & $4.0 \%$ \\
\hline & Unanswered & 5 & $2.2 \%$ & 7 & $3.1 \%$ \\
\hline \multirow{3}{*}{$\begin{array}{l}\text { CDP } \\
2005\end{array}$} & Numerical Response & 170 & $64.2 \%$ & 214 & $80.8 \%$ \\
\hline & WRI GHG Protocol & 17 & $6.4 \%$ & 17 & $6.4 \%$ \\
\hline & Unanswered & 2 & $0.8 \%$ & 4 & $1.5 \%$ \\
\hline \multirow{3}{*}{$\begin{array}{l}\text { CDP } \\
2006\end{array}$} & Numerical Response & 440 & $74.8 \%$ & 313 & $53.2 \%$ \\
\hline & WRI GHG Protocol & 143 & $24.3 \%$ & 16 & $2.7 \%$ \\
\hline & Unanswered & 30 & $5.1 \%$ & 38 & $6.5 \%$ \\
\hline
\end{tabular}




\begin{tabular}{|c|c|c|c|c|c|c|c|}
\hline & & 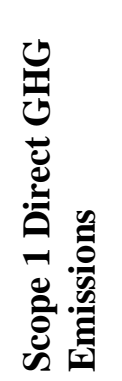 & 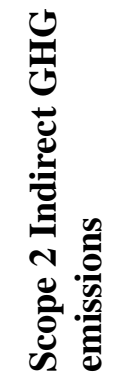 & 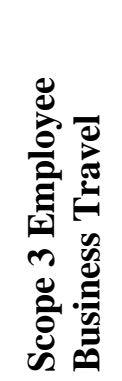 & 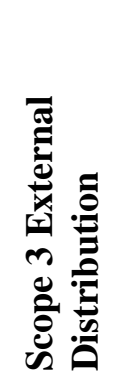 & 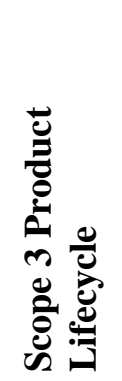 & 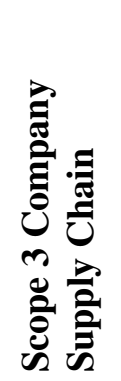 \\
\hline \multirow[t]{2}{*}{ CDP 2007} & Numerical Response & $55.6 \%$ & $48.6 \%$ & $17.8 \%$ & $9.7 \%$ & $8.2 \%$ & $6.1 \%$ \\
\hline & Unanswered & $44.4 \%$ & $51.4 \%$ & $82.2 \%$ & $90.3 \%$ & $91.8 \%$ & $93.9 \%$ \\
\hline \multirow[t]{2}{*}{ CDP 2008} & Numerical Response & $53.8 \%$ & $49.3 \%$ & $24.4 \%$ & $10.0 \%$ & $7.2 \%$ & $6.2 \%$ \\
\hline & Unanswered & $46.2 \%$ & $50.7 \%$ & $75.6 \%$ & $90.0 \%$ & $92.8 \%$ & $93.8 \%$ \\
\hline \multirow[t]{2}{*}{ CDP 2009} & Numerical Response & $74.8 \%$ & $71.3 \%$ & N/A & N/A & N/A & N/A \\
\hline & Unanswered & $25.2 \%$ & $28.7 \%$ & & & & \\
\hline \multirow[t]{2}{*}{ CDP 2010} & Numerical Response & $68.0 \%$ & $67.6 \%$ & $44.2 \%$ & $12.8 \%$ & $7.0 \%$ & $6.2 \%$ \\
\hline & Unanswered & $32.0 \%$ & $32.4 \%$ & $55.8 \%$ & $87.2 \%$ & $93.0 \%$ & $93.8 \%$ \\
\hline
\end{tabular}


Table 4: Scope 1 Emissions Reporting for CDP2007-CDP2008 (Percent by Industrial Sector)

\begin{tabular}{lrrrr}
\hline & CDP2007 & CDP2008 & CDP2009 & CDP2010 \\
\hline $\begin{array}{l}\text { Consumer } \\
\text { Discretionary }\end{array}$ & $51.4 \%$ & $49.6 \%$ & $69.8 \%$ & $56.4 \%$ \\
Consumer Staples & $71.6 \%$ & $66.3 \%$ & $89.7 \%$ & $78.2 \%$ \\
Energy & $64.3 \%$ & $62.1 \%$ & $82.4 \%$ & $75.9 \%$ \\
Financials & $64.0 \%$ & $49.5 \%$ & $61.8 \%$ & $56.6 \%$ \\
Health Care & $43.5 \%$ & $37.0 \%$ & $17.5 \%$ & $28.8 \%$ \\
Industrials & $45.0 \%$ & $48.1 \%$ & $77.4 \%$ & $69.7 \%$ \\
Information & $60.0 \%$ & $55.3 \%$ & $79.6 \%$ & $80.3 \%$ \\
Technology & & & & \\
Materials & $53.2 \%$ & $61.6 \%$ & $84.1 \%$ & $75.9 \%$ \\
Telecommunications & $51.1 \%$ & $44.7 \%$ & $19.2 \%$ & $27.0 \%$ \\
\hline Utilities & $40.0 \%$ & $54.7 \%$ & $30.9 \%$ & $38.9 \%$ \\
\hline
\end{tabular}


Table 5: Scope 1 Emissions Reporting for CDP2007-CDP2008 (Percent of firms reporting in region)

\begin{tabular}{lrrrr}
\hline & CDP2007 & CDP2008 & CDP2009 & CDP2010 \\
\hline Europe & $56.8 \%$ & $58.1 \%$ & $79.8 \%$ & $65.7 \%$ \\
Japan & $56.2 \%$ & $62.8 \%$ & $54.5 \%$ & $76.9 \%$ \\
Other & $60.2 \%$ & $43.0 \%$ & $67.6 \%$ & $62.0 \%$ \\
US & $58.4 \%$ & $58.2 \%$ & $81.8 \%$ & $24.6 \%$ \\
\hline
\end{tabular}


Table 6. External Verification of Emissions (2007 - 2010)

\begin{tabular}{|c|c|c|}
\hline \multirow{2}{*}{$\begin{array}{c}\text { CDP } \\
\mathbf{2 0 0 7}\end{array}$} & Unanswered & $15.8 \%$ \\
\cline { 2 - 3 } & No & $42.5 \%$ \\
\cline { 2 - 3 } & Yes & $41.7 \%$ \\
\hline \multirow{2}{*}{$\mathbf{C D P}$} & Unanswered & $29.6 \%$ \\
\cline { 2 - 3 } $\mathbf{2 0 0 8}$ & No & $34.2 \%$ \\
\cline { 2 - 3 } & Yes & $36.2 \%$ \\
\hline \multirow{2}{*}{$\mathbf{C D P}$} & Unanswered & $17.3 \%$ \\
\cline { 2 - 3 } $\mathbf{2 0 0 9}$ & No & $32.3 \%$ \\
\cline { 2 - 3 } & Yes & $43.8 \%$ \\
\hline \multirow{2}{*}{$\mathbf{C D P}$} & Unanswered & $20.8 \%$ \\
\cline { 2 - 3 } $\mathbf{2 0 1 0}$ & No & $41.3 \%$ \\
\cline { 2 - 3 } & Yes & $44.4 \%$ \\
\hline
\end{tabular}


Table 7: HHI index of top 100 keywords (2007 - 2010)

\begin{tabular}{|l|l|}
\hline & \multicolumn{2}{|l|}{ HHI Top } \\
$\mathbf{1 0 0}$ \\
\hline 2007 & 184 \\
\hline 2008 & 208 \\
\hline 2009 & 171 \\
\hline 2010 & 357 \\
\hline
\end{tabular}


Table 8. Implementation of selected standards by firms

\begin{tabular}{|c|c|c|c|c|c|c|c|c|c|c|c|c|c|c|c|c|}
\hline 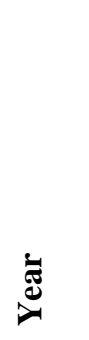 & 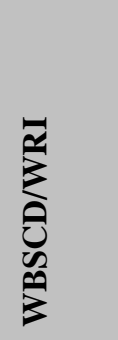 & 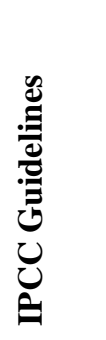 & $\frac{\nwarrow}{\frac{\Omega}{c}}$ & ○ & 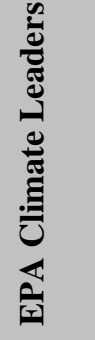 & 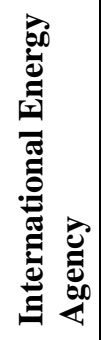 & 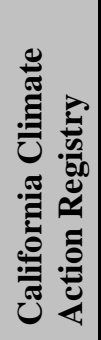 & 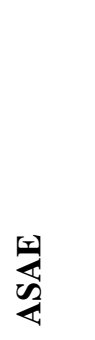 & 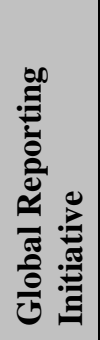 & 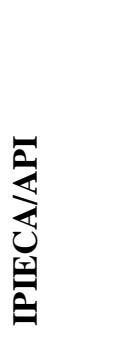 & 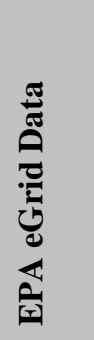 & 总 & 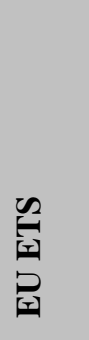 & O্ & $\stackrel{\mathrm{e}}{\mathrm{e}}$ & $\underset{u}{x}$ \\
\hline 2007 & $44.9 \%$ & $4.0 \%$ & $4.7 \%$ & $1.4 \%$ & $3.6 \%$ & $1.4 \%$ & $0.8 \%$ & $3.4 \%$ & $1.6 \%$ & $2.4 \%$ & $0.4 \%$ & $0.9 \%$ & $1.8 \%$ & $0.3 \%$ & $0.3 \%$ & $0.2 \%$ \\
\hline 2008 & $47.4 \%$ & $6.6 \%$ & $6.2 \%$ & $4.0 \%$ & $4.2 \%$ & $2.9 \%$ & $2.2 \%$ & $3.8 \%$ & $1.8 \%$ & $2.2 \%$ & $1.4 \%$ & $1.7 \%$ & $1.7 \%$ & $0.7 \%$ & $0.4 \%$ & $0.5 \%$ \\
\hline 2009 & $59.7 \%$ & $10.7 \%$ & $9.4 \%$ & $9.0 \%$ & $6.5 \%$ & $5.0 \%$ & $4.6 \%$ & $4.6 \%$ & $3.9 \%$ & $3.5 \%$ & $3.3 \%$ & $3.2 \%$ & $2.8 \%$ & $0.8 \%$ & $0.8 \%$ & $0.7 \%$ \\
\hline 2010 & $63.4 \%$ & $11.3 \%$ & $12.2 \%$ & $10.6 \%$ & $6.7 \%$ & $2.9 \%$ & $4.3 \%$ & $2.4 \%$ & $3.3 \%$ & $3.1 \%$ & $2.0 \%$ & $2.7 \%$ & $2.4 \%$ & $0.8 \%$ & $0.7 \%$ & $0.4 \%$ \\
\hline
\end{tabular}




\section{Appendices:}

\section{Appendix A: Descriptions of Selected Protocols WBSCD/WRI Greenhouse Gas Protocol}

The World Business Council for Sustainable Development/ World Resources Institute (WBSCD/WRI) Greenhouse Gas Protocol is developed in collaboration with multiple private, public, and non-governmental organizations to provide an internationally recognized standard for accounting and reporting greenhouse gases (WBSCD/WRI, 2004). The Greenhouse Gas Protocol publishes standards for multiple aspects of greenhouse gas accounting, including the GHG Protocol Corporate Accounting and Reporting Standard, GHG Protocol Project Quantification Standard, and a recently released standard on Scope 3 emissions.

\section{International Standard on Assurance Engagements 3000 (ISAE 3000) from the International Federation of Accountants}

The ISAE 3000 was created by the International Auditing and Assurance Standards Board (IAASB) to provide professional accounting instructions to public practitioners of accounting. It is not explicitly developed to address environmental management or greenhouse gas emissions, but the framework is adaptable. It seeks to establish convergence upon an international, professional accounting standard for assurance engagements other than audits or reviews of historical financial information (IAASB, 2008).

\section{International Organizations for Standardization (ISO)}

The ISO is a Geneva based NGO made up of standards institutes from 162 countries. It claims to be the largest developer and publisher of international standards. ISO partners represent both private and public interests. They have published hundreds of standards at present, and many have been referenced in the CDP. All standards are voluntary and developed for areas where there is a definite market requirement (ISO, 2011).

\section{Global Reporting Initiative (GRI) Sustainability Reporting Guidelines}

Though the Sustainability Reporting Guidelines, GRI (established in 1997) seeks to promote sustainability by encouraging greater transparency of the impacts of firm activities. GRI develops its reporting framework through consultation with actors in a network of diverse stakeholders (business, investors, labor, civil society, accounting, academia, and others). Unlike other standards, this framework provides guidelines for accounting economic and social impacts, in addition to environmental impacts (Global Reporting Initiative, 2011).

\section{AA1000AS (2008) Assurance Standard from Accountability}

In 2003, the AA1000 was published by AccountAbility as the world's first sustainability insurance standard. It was developed in collaboration with international stakeholders, such as investors, businesses, and NGOs. Sustainability insurance addresses the adherence to AA1000 Accountability Principles and the quality of disclosed information pertaining to sustainability. It is intended to be used by sustainability insurance practitioners, report preparers, and users of sustainability reports. AccountAbility is a nonprofit, international network dedicated to encouraging accountability innovations related to sustainability (AccountAbility, 2008). 


\section{EPA Climate Leader Standards}

From 2002 to 2011, the EPA Climate Leaders program was a partnership between the EPA and private firms to improve the environmental performance of American businesses. The Climate Leaders program differed from the GHG Protocol as it was a program based out of the United States dealing directly with setting environmental performance goals and recognizing related leadership and achievement of American businesses (Environmental Protection Agency, 2011), as opposed to international greenhouse gas reporting and accounting standards. Following September 2011, the Climate Leaders program was ended in response to the maturity of alternate state and NGO operated climate programs, as well as a new EPA Greenhouse Gas Reporting Program (McCarthy, 2010).

\section{European Union Emissions Trading Scheme (EU ETS)}

Inspired by the Kyoto Protocol, EU ETS was established in 2005 as a mandatory cap and trade system designed for European Union member nations to reach their carbon reduction goals. As a carbon trading scheme, it quantifies carbon emissions through the use of a price mechanism. The total emission released by a firm is determined by how much carbon has been bought or sold (European Commission, 2009).

\section{California Climate Action Registry (CCAR)}

Developed by the California Registry (transitioning to the Climate Registry) in 2001 to encourage greenhouse gas emissions reporting, CCAR was a voluntary program of special interest to public, private, and environmental organizations. In December 2010, CCAR was officially closed. During its time, it received 863 verified Greenhouse gas emissions reports, including 972,802,087.81 metric tons CO2e of direct and indirect emissions(California Climate Action Registry, 2011).

\section{Chicago Climate Exchange (CCX)}

Launched in 2003, CCX was the United States' first carbon emissions cap and trade program. It reported 450 members and greenhouse gas emissions reductions of 700 million tons. In 2010, it ended its carbon emission program but launched the Chicago Climate Exchange Offsets Registry Program in January 2011 (Chicago Climate Exchange, 2011; Gronewold, January 3, 2011).

\section{Standards on Engagements (ASAE)}

ASAE is a product of the Australian Government Auditing and Assurance Standards Board (AUASB). As dictated by Australian law, the AUASB publishes the ASAE to establish "mandatory requirements and provides explanatory guidance for undertaking and reporting on assurance engagements other than audits or reviews of historical financial information covered by Auditing Standards (ASAs) or Auditing Standards on Review Engagements (ASREs)” (AUASB, 2007).

\section{Intergovernmental Panel on Climate Change (IPCC) Guidelines}

Established by the United Nations Environment Programme (UNEP) and the World Meteorological Organization (WMO) to provide the international community with scientific information pertaining to climate change, IPCC is responsible for publications pertaining to 
greenhouse gas emissions accounting methodology, which are utilized by some responding firms (Intergovernmental Panel on Climate Change, 2011).

\section{Carbon Trust Standard}

Since 2008, the Carbon Trust Standard has been produced by the Carbon Trust to promote accounting, management, and reduction of greenhouse gas emissions of both public and private organizations. It is influenced by WRI's GHG Protocol and ISO 14064-1 and was developed with the help of major private and public organizations (Carbon Trust, 2011).

\section{Environmental Management Systems (EMS)}

EMS is produced by the US Environmental Protection Agency to provide guidance to firms trying to reduce their environmental impact. It is designed to help firms develop affordable environmental management programs (EPA, 2012)

\section{Third-Party Verification Standards}

Some firms mention, by name, a third-party contractor responsible for externally verifying their response. Common third-parties include: Price Waterhouse Coopers, Det Norske Veritas, Deloitte, KPMG, and Bureau Veritas. 
Appendix B: Characteristics of Selected Protocols

\begin{tabular}{|c|c|c|}
\hline Standard & Required Information & Primary Goal(s) \\
\hline $\begin{array}{l}\text { WBSCD/WRI } \\
\text { Greenhouse Gas } \\
\text { Protocol }\end{array}$ & 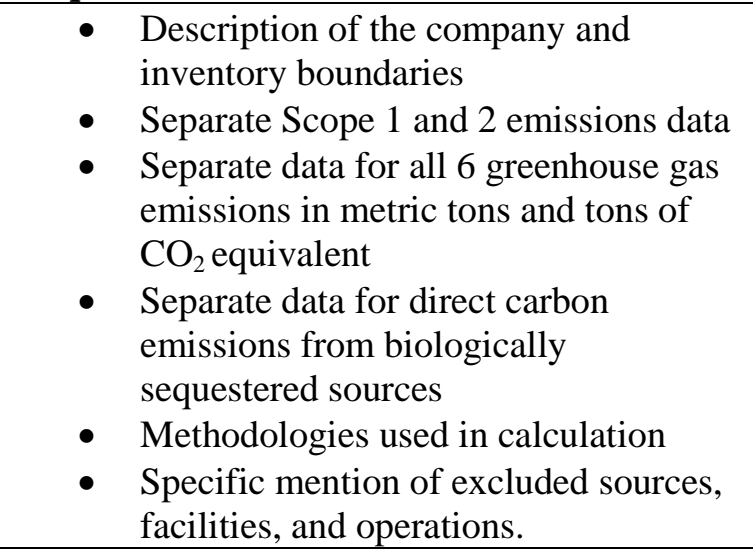 & $\begin{array}{l}\text { "To develop internationally } \\
\text { accepted greenhouse gas (GHG) } \\
\text { Accounting and reporting } \\
\text { standards for business and to } \\
\text { promote their broad adoption” } \\
\text { (WBSCD/WRI, 2004) }\end{array}$ \\
\hline ISO 14064-1 & $\begin{array}{ll}\text { - } & \text { Organizational level reporting } \\
\text { - } & \text { Project level reporting } \\
\text { - } & \text { Validation and Verifications }\end{array}$ & $\begin{array}{l}\text { - To encourage and promote } \\
\text { consistency, transparency, } \\
\text { and credibility in } \\
\text { greenhouse gas reporting } \\
\text { - To allow organizations to } \\
\text { identify their sources of } \\
\text { greenhouse gas emissions } \\
\text { - To enable the trade of } \\
\text { GHG allowances and } \\
\text { credits } \\
\text { "support the design, } \\
\text { development and } \\
\text { implementation of } \\
\text { comparable and consistent } \\
\text { GHG schemes or } \\
\text { programmes.” }\end{array}$ \\
\hline IPCC & $\begin{array}{l}\text { - Varies by Sector } \\
\text { - Activity Data x Emissions Factors = } \\
\text { GHG Emissions } \\
\text { *Activity Data is human activity involved in } \\
\text { creating emissions. Emissions factors are the } \\
\text { quantifications of emissions units produced per } \\
\text { unit of activity data }\end{array}$ & $\begin{array}{l}\text { IPCC aims to assist the Parties to } \\
\text { the UNFCCC in "fulfilling their } \\
\text { commitments under the UNFCCC } \\
\text { on reporting on } \\
\text { inventories of anthropogenic } \\
\text { emissions by sources and removals } \\
\text { by sinks of greenhouse gases not } \\
\text { controlled by } \\
\text { the Montreal Protocol, as agreed } \\
\text { by the Parties" (IPCC, 2006). }\end{array}$ \\
\hline DEFRA & $\begin{array}{l}\text { Activity Data x Emissions Factors = GHG } \\
\text { Emissions } \\
12 \text { Recommendations: } \\
\text { 1. “Apply your chosen approach } \\
\text { consistently and for most organisations } \\
\text { this will be the financial control } \\
\text { approach' }\end{array}$ & $\begin{aligned} & \text { To assist UK organizations in : } \\
& \text { - } \text { Reducing contributions to } \\
& \text { climate change } \\
& \text { - } \text { Setting GHG Reduction } \\
& \text { targets } \\
& \text { - } \text { Measuring total GHG } \\
& \text { emissions (DEFRA, 2009) }\end{aligned}$ \\
\hline
\end{tabular}




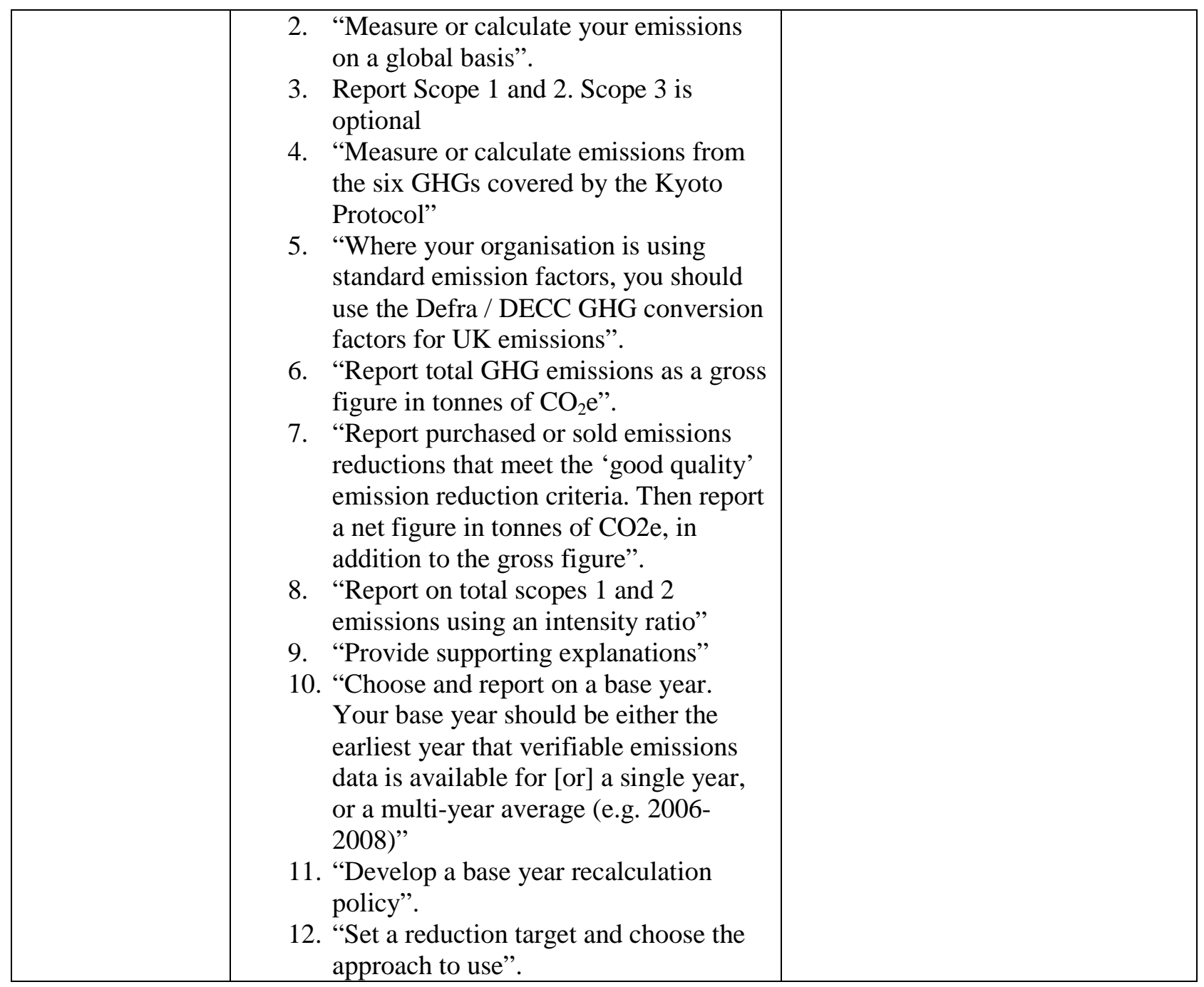


Appendix C. Implementation of standards by region

Europe

\begin{tabular}{|c|c|c|c|c|c|c|c|c|c|}
\hline & 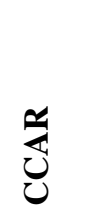 & $\begin{array}{l}\frac{1}{2} \\
\substack{1 \\
1} \\
0\end{array}$ & 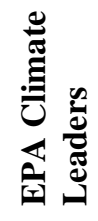 & 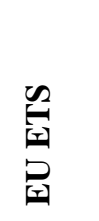 & శ্র & ن & 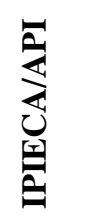 & O & 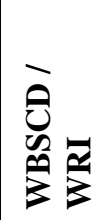 \\
\hline 2007 & $0 \%$ & $10.7 \%$ & $0 \%$ & $3.6 \%$ & $1.6 \%$ & $3.6 \%$ & $1.3 \%$ & $1.3 \%$ & $41.1 \%$ \\
\hline 2008 & $0.4 \%$ & $12.8 \%$ & $0 \%$ & $3.6 \%$ & $3.0 \%$ & $6.2 \%$ & $1.6 \%$ & $4.2 \%$ & $47.7 \%$ \\
\hline 2009 & $1.2 \%$ & $20.0 \%$ & $0.2 \%$ & $5.9 \%$ & $6.9 \%$ & $9.6 \%$ & $2.4 \%$ & $10.0 \%$ & $54.7 \%$ \\
\hline 2010 & $0.4 \%$ & $23.7 \%$ & $0.8 \%$ & $5.1 \%$ & $5.7 \%$ & $8.9 \%$ & $1.9 \%$ & $8.3 \%$ & $66.8 \%$ \\
\hline
\end{tabular}

Japan

\begin{tabular}{|c|c|c|c|c|c|c|c|c|c|}
\hline & $\sum_{u}^{\frac{x}{u}}$ & 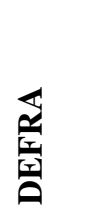 & 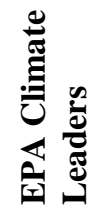 & 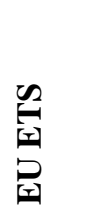 & $\overrightarrow{\underline{v}}$ & U: & $\sum_{\substack{\mathbf{1} \\
\mathbf{a}}}^{\bar{a}}$ & $\stackrel{\varrho}{\mathscr{G}}$ & 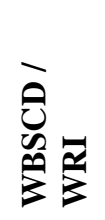 \\
\hline 2007 & $0 \%$ & $0 \%$ & $0 \%$ & $0 \%$ & $0 \%$ & $2.7 \%$ & $0 \%$ & $0 \%$ & $30.1 \%$ \\
\hline 2008 & $0 \%$ & $0 \%$ & $0 \%$ & $0 \%$ & $0 \%$ & $2.6 \%$ & $0 \%$ & $2.6 \%$ & $30.8 \%$ \\
\hline 2009 & $0 \%$ & $0 \%$ & $0 \%$ & $0 \%$ & $0 \%$ & $1.8 \%$ & $0 \%$ & $2.7 \%$ & $10.7 \%$ \\
\hline 2010 & $0.8 \%$ & $1.7 \%$ & $0.0 \%$ & $0.0 \%$ & $0.8 \%$ & $4.1 \%$ & $0.0 \%$ & $5.8 \%$ & $28.9 \%$ \\
\hline
\end{tabular}

United States

\begin{tabular}{|c|c|c|c|c|c|c|c|c|c|}
\hline & 苨 & 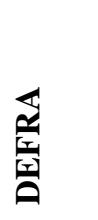 & 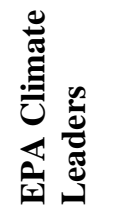 & 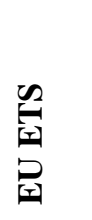 & 胥 & U & $\sum_{\substack{\mathbf{d} \\
\mathbf{e}}}^{\bar{a}}$ & @ & $\begin{array}{l}\hat{\theta} \\
\mathscr{N}^{n} \\
\sum_{3}^{n}\end{array}$ \\
\hline 2007 & $2.9 \%$ & $0 \%$ & $13.5 \%$ & $0.4 \%$ & $0.8 \%$ & $2.9 \%$ & $4.1 \%$ & $0 \%$ & $55.5 \%$ \\
\hline 2008 & $8.2 \%$ & $1.6 \%$ & $17.0 \%$ & $0.9 \%$ & $0.9 \%$ & $6.3 \%$ & $3.8 \%$ & $0.3 \%$ & $61.0 \%$ \\
\hline 2009 & $16.2 \%$ & $1.3 \%$ & $26.4 \%$ & $0.7 \%$ & $1.7 \%$ & $10.6 \%$ & $5.6 \%$ & $2.6 \%$ & $71.3 \%$ \\
\hline
\end{tabular}




\begin{tabular}{|l|l|l|l|l|l|l|l|l|l|}
\hline $\mathbf{2 0 1 0}$ & $15.1 \%$ & $3.9 \%$ & $27.0 \%$ & $0.0 \%$ & $1.6 \%$ & $6.9 \%$ & $5.6 \%$ & $3.0 \%$ & $74.3 \%$ \\
\hline
\end{tabular}

Appendix D. Implementation of standards by industry

Consumer Discretionary

\begin{tabular}{|c|c|c|c|c|c|c|c|c|c|}
\hline & $\sum_{0}^{\mathscr{c}}$ & 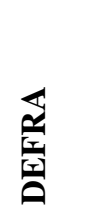 & 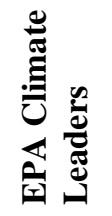 & 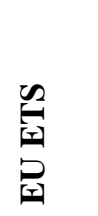 & 胥 & ن & 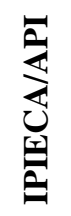 & $\stackrel{0}{\mathscr{G}}$ & 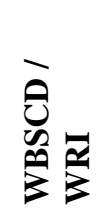 \\
\hline 2007 & $0 \%$ & $6.8 \%$ & $2.7 \%$ & $0 \%$ & $1.4 \%$ & $4.1 \%$ & $0 \%$ & $2.7 \%$ & $45.9 \%$ \\
\hline 2008 & $1.6 \%$ & $6.3 \%$ & $4.7 \%$ & $0 \%$ & $0.8 \%$ & $6.3 \%$ & $0 \%$ & $3.9 \%$ & $48 \%$ \\
\hline 2009 & $0 \%$ & $15.1 \%$ & $7.5 \%$ & $0.9 \%$ & $3.8 \%$ & $8.5 \%$ & $0 \%$ & $7.5 \%$ & $58.5 \%$ \\
\hline 2010 & $0.6 \%$ & $21.3 \%$ & $10.4 \%$ & $0.6 \%$ & $3.0 \%$ & $11.0 \%$ & $0 \%$ & $9.1 \%$ & $62.8 \%$ \\
\hline
\end{tabular}

Consumer Staples

\begin{tabular}{|c|c|c|c|c|c|c|c|c|c|}
\hline & 苍 & 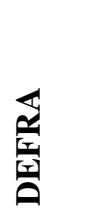 & 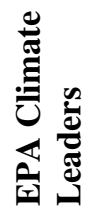 & 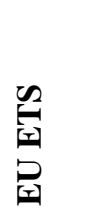 & 원 & ن & 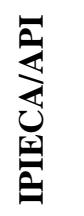 & @ొ & 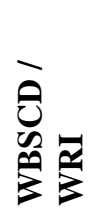 \\
\hline 2007 & $0 \%$ & $6.2 \%$ & $6.2 \%$ & $1.2 \%$ & $1.2 \%$ & $8.6 \%$ & $0 \%$ & $0 \%$ & $54.3 \%$ \\
\hline 2008 & $4.0 \%$ & $4.0 \%$ & $6.9 \%$ & $3.0 \%$ & $3.0 \%$ & $9.9 \%$ & $0 \%$ & $1.0 \%$ & $66.3 \%$ \\
\hline 2009 & $5.0 \%$ & $9.0 \%$ & $12.0 \%$ & $4.0 \%$ & $4.0 \%$ & $16.0 \%$ & $0 \%$ & $4.0 \%$ & $64.0 \%$ \\
\hline 2010 & $8.0 \%$ & $13.0 \%$ & $14.0 \%$ & $0.0 \%$ & $4.0 \%$ & $16.0 \%$ & $0.0 \%$ & $10.0 \%$ & $79.0 \%$ \\
\hline
\end{tabular}

\section{Energy}

\begin{tabular}{|c|c|c|c|c|c|c|c|c|c|}
\hline & $\sum_{u}^{\frac{3}{u}}$ & 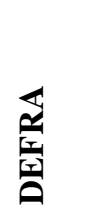 & 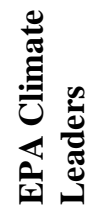 & $\begin{array}{l}n \\
\underbrace{}_{11} \\
D \\
D\end{array}$ & 胥 & ن. & 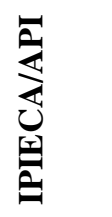 & $\stackrel{\varrho}{\mathscr{Q}}$ & 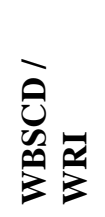 \\
\hline 2007 & $1.4 \%$ & $1.4 \%$ & $0 \%$ & $7.1 \%$ & $7.1 \%$ & $1.4 \%$ & $31.4 \%$ & $2.9 \%$ & $51.4 \%$ \\
\hline 2008 & $4.9 \%$ & $1.0 \%$ & $0 \%$ & $7.8 \%$ & $5.8 \%$ & $6.8 \%$ & $27.2 \%$ & $3.9 \%$ & $47.6 \%$ \\
\hline
\end{tabular}




\begin{tabular}{|l|l|l|l|l|l|l|l|l|l|}
\hline $\mathbf{2 0 0 9}$ & $2.4 \%$ & $3.5 \%$ & $0 \%$ & $10.6 \%$ & $5.9 \%$ & $9.4 \%$ & $43.5 \%$ & $8.2 \%$ & $47.1 \%$ \\
\hline $\mathbf{2 0 1 0}$ & $6.0 \%$ & $4.8 \%$ & $1.2 \%$ & $7.2 \%$ & $4.8 \%$ & $6.0 \%$ & $42.2 \%$ & $10.8 \%$ & $44.6 \%$ \\
\hline
\end{tabular}

Financials

\begin{tabular}{|c|c|c|c|c|c|c|c|c|c|}
\hline & ن্ত & 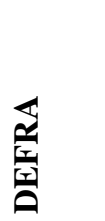 & 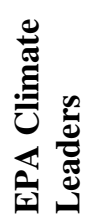 & 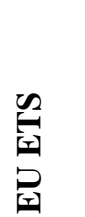 & 趈 & نِ & 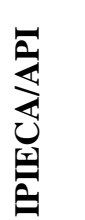 & @ొ & 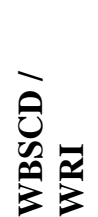 \\
\hline 2007 & $0 \%$ & $9.9 \%$ & $2.0 \%$ & $1.0 \%$ & $2.5 \%$ & $1.5 \%$ & $0 \%$ & $2.0 \%$ & $38.4 \%$ \\
\hline 2008 & $0.3 \%$ & $13.4 \%$ & $2.1 \%$ & $0.3 \%$ & $1.7 \%$ & $3.8 \%$ & $0 \%$ & $4.8 \%$ & $41.9 \%$ \\
\hline 2009 & $0.7 \%$ & $15.4 \%$ & $2.6 \%$ & $0.4 \%$ & $2.6 \%$ & $4.5 \%$ & $0 \%$ & $6.4 \%$ & $46.1 \%$ \\
\hline 2010 & $2.1 \%$ & $17.9 \%$ & $5.1 \%$ & $0.4 \%$ & $3.4 \%$ & $9.8 \%$ & $0.0 \%$ & $8.1 \%$ & $66.0 \%$ \\
\hline
\end{tabular}

Health Care

\begin{tabular}{|c|c|c|c|c|c|c|c|c|c|}
\hline & $\underbrace{\frac{n}{u}}_{0}$ & 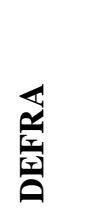 & 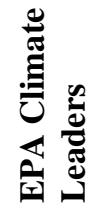 & 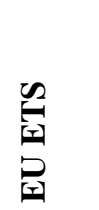 & శ్ & نُ & $\sum_{\substack{\mathbf{d} \\
\mathbf{Q}}}^{\bar{Q}}$ & $\stackrel{0}{\mathscr{\Omega}}$ & 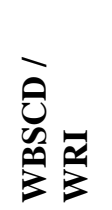 \\
\hline 2007 & $2.2 \%$ & $0 \%$ & $6.5 \%$ & $0 \%$ & $2.2 \%$ & $0 \%$ & $0 \%$ & $0 \%$ & $56.5 \%$ \\
\hline 2008 & $5.6 \%$ & $1.9 \%$ & $9.3 \%$ & $0 \%$ & $0 \%$ & $1.9 \%$ & $0 \%$ & $5.6 \%$ & $57.4 \%$ \\
\hline 2009 & $6.5 \%$ & $4.8 \%$ & $12.9 \%$ & $0 \%$ & $3.2 \%$ & $6.5 \%$ & $0 \%$ & $8.1 \%$ & $67.7 \%$ \\
\hline 2010 & $6.2 \%$ & $4.6 \%$ & $13.8 \%$ & $0.0 \%$ & $1.5 \%$ & $6.2 \%$ & $0.0 \%$ & $4.6 \%$ & $70.8 \%$ \\
\hline
\end{tabular}

Industrials

\begin{tabular}{|c|c|c|c|c|c|c|c|c|c|}
\hline & $\sum_{0}^{\underline{x}}$ & $\begin{array}{l}\frac{\pi}{2} \\
\frac{1}{11} \\
\frac{11}{0}\end{array}$ & 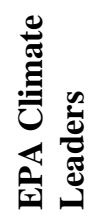 & 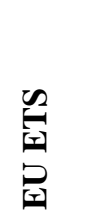 & 胥 & نُّ & 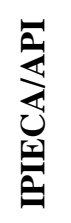 & $\stackrel{0}{\mathscr{Q}}$ & 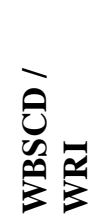 \\
\hline 2007 & $0.7 \%$ & $4.0 \%$ & $4.6 \%$ & $1.3 \%$ & $1.3 \%$ & $1.3 \%$ & $0 \%$ & $0.7 \%$ & $41.1 \%$ \\
\hline 2008 & $0.8 \%$ & $5.8 \%$ & $5.0 \%$ & $0 \%$ & $1.7 \%$ & $4.1 \%$ & $0 \%$ & $3.7 \%$ & $44.0 \%$ \\
\hline
\end{tabular}




\begin{tabular}{|l|l|l|l|l|l|l|l|l|l|}
\hline $\mathbf{2 0 0 9}$ & $4.7 \%$ & $11.1 \%$ & $4.7 \%$ & $1.7 \%$ & $5.1 \%$ & $8.5 \%$ & $0 \%$ & $10.3 \%$ & $54.7 \%$ \\
\hline $\mathbf{2 0 1 0}$ & $3.3 \%$ & $15.9 \%$ & $3.8 \%$ & $0.4 \%$ & $3.8 \%$ & $7.5 \%$ & $0.0 \%$ & $10.0 \%$ & $60.3 \%$ \\
\hline
\end{tabular}

Information Technology

\begin{tabular}{|c|c|c|c|c|c|c|c|c|c|}
\hline & 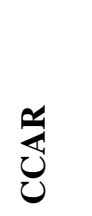 & 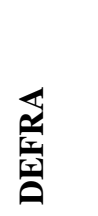 & 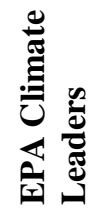 & $\begin{array}{l}n \\
0 \\
0 \\
D \\
D\end{array}$ & శ్ & U & $\sum_{\substack{\mathbf{1} \\
\mathbf{a}}}^{\bar{a}}$ & @ి & $\begin{array}{l}\hat{\theta} \\
\text { W } \\
\text { 孚 }\end{array}$ \\
\hline 2007 & $3.1 \%$ & $0 \%$ & $9.2 \%$ & $0 \%$ & $0 \%$ & $12.3 \%$ & $0 \%$ & $0 \%$ & $52.3 \%$ \\
\hline 2008 & $2.6 \%$ & $1.3 \%$ & $11.8 \%$ & $0 \%$ & $0 \%$ & $14.5 \%$ & $0 \%$ & $5.3 \%$ & $61.8 \%$ \\
\hline 2009 & $5.6 \%$ & $5.6 \%$ & $13.9 \%$ & $0.9 \%$ & $1.9 \%$ & $18.5 \%$ & $0 \%$ & $16.7 \%$ & $65.7 \%$ \\
\hline 2010 & $3.9 \%$ & $5.5 \%$ & $11.8 \%$ & $0.8 \%$ & $1.6 \%$ & $21.3 \%$ & $0.0 \%$ & $22.8 \%$ & $75.6 \%$ \\
\hline
\end{tabular}

\section{Materials}

\begin{tabular}{|c|c|c|c|c|c|c|c|c|c|}
\hline & $\underbrace{\mathbb{x}}_{0}$ & 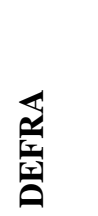 & 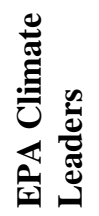 & 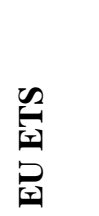 & 胥 & ن & 式 & ○ి & 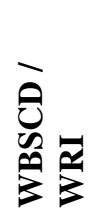 \\
\hline 2007 & $0 \%$ & $1.1 \%$ & $2.1 \%$ & $2.1 \%$ & $0 \%$ & $9.6 \%$ & $0 \%$ & $3.2 \%$ & $47.9 \%$ \\
\hline 2008 & $1.6 \%$ & $1.6 \%$ & $2.4 \%$ & $1.6 \%$ & $2.4 \%$ & $9.6 \%$ & $0.8 \%$ & $4.8 \%$ & $37.6 \%$ \\
\hline 2009 & $2.3 \%$ & $2.3 \%$ & $3.8 \%$ & $3.0 \%$ & $3.0 \%$ & $16.7 \%$ & $1.5 \%$ & $6.1 \%$ & $52.3 \%$ \\
\hline 2010 & $1.9 \%$ & $4.4 \%$ & $3.2 \%$ & $5.1 \%$ & $2.5 \%$ & $13.3 \%$ & $0.6 \%$ & $9.5 \%$ & $60.1 \%$ \\
\hline
\end{tabular}

Telecommunications

\begin{tabular}{|c|c|c|c|c|c|c|c|c|c|}
\hline & 苍 & 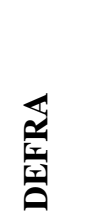 & 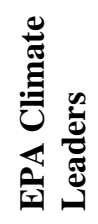 & $\begin{array}{l}\infty \\
\underset{1}{n} \\
D \\
D\end{array}$ & 胥 & ن. & 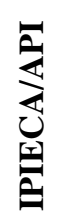 & 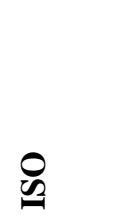 & 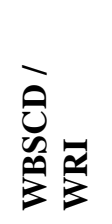 \\
\hline 2007 & $2.2 \%$ & $4.4 \%$ & $0 \%$ & $0 \%$ & $0 \%$ & $2.2 \%$ & $0 \%$ & $2.2 \%$ & $37.8 \%$ \\
\hline 2008 & $4.3 \%$ & $4.3 \%$ & $2.1 \%$ & $0 \%$ & $0 \%$ & $4.3 \%$ & $0 \%$ & $4.3 \%$ & $55.3 \%$ \\
\hline 2009 & $7.7 \%$ & $0 \%$ & $7.7 \%$ & $0 \%$ & $3.8 \%$ & 7.7\% & $0 \%$ & $13.5 \%$ & $57.7 \%$ \\
\hline
\end{tabular}




\begin{tabular}{|l|l|l|l|l|l|l|l|l|l|}
\hline $\mathbf{2 0 1 0}$ & $5.6 \%$ & $8.3 \%$ & $5.6 \%$ & $0.0 \%$ & $2.8 \%$ & $8.3 \%$ & $0.0 \%$ & $16.7 \%$ & $69.4 \%$ \\
\hline
\end{tabular}

\section{Utilities}

\begin{tabular}{|c|c|c|c|c|c|c|c|c|c|}
\hline & 芯 & 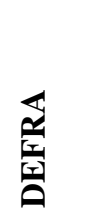 & 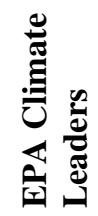 & 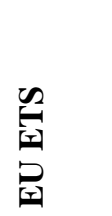 & 胥 & U & 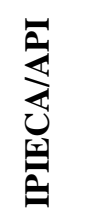 & @ & 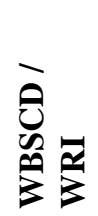 \\
\hline 2007 & $1.3 \%$ & $3.8 \%$ & $5.0 \%$ & $6.3 \%$ & $0 \%$ & $3.8 \%$ & $0 \%$ & $0 \%$ & $40.0 \%$ \\
\hline 2008 & $3.8 \%$ & $5.7 \%$ & $6.6 \%$ & $7.5 \%$ & $0.9 \%$ & $13.2 \%$ & $0 \%$ & $3.8 \%$ & $38.7 \%$ \\
\hline 2009 & $12.7 \%$ & $7.3 \%$ & $7.3 \%$ & $10.0 \%$ & $6.4 \%$ & $15.5 \%$ & $4.5 \%$ & $12.7 \%$ & $40.0 \%$ \\
\hline 2010 & $13.9 \%$ & $7.4 \%$ & $3.7 \%$ & $12.0 \%$ & $5.6 \%$ & $13.0 \%$ & $4.6 \%$ & $9.3 \%$ & $50.0 \%$ \\
\hline
\end{tabular}

